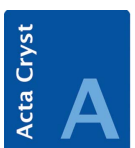

Keywords: International Union of Crystallography; Executive Committee.

Supporting information: this article has supporting information at journals.iucr.org/a

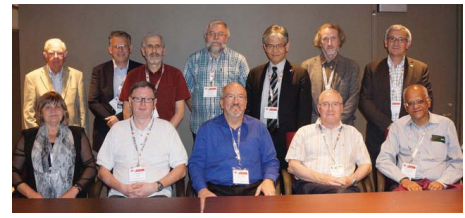

(C) 2017 International Union of Crystallography

\section{Report of the Executive Committee for 2015}

\section{Meetings}

The IUCr sponsored the following meetings held during 2015:

Computational Materials Discovery Using the USPEX Code, Shiv Nadar, India, 20-24

January.

Asian XD Charge Density Workshop, Bangalore, India, 16-18 February.

Fifth Winter School on Soft X-rays in Macromolecular Crystallography, Athens, GA, USA, 28 February - 3 March.

XV Intensive Teaching School in X-ray Structure Analysis, Durham, UK, 21-29 March.

Macromolecular Crystallography School 2015: From Data Processing to Structure

Refinement and Beyond, Montevideo, Uruguay, 6-15 April.

3rd School on Crystal Structure Determination From Diffraction Data: Application to

Powder Samples, Sousse, Tunisia, 9-12 April.

RapiData 2015, Stanford, USA, 26 April - 1 May.

5th International School on Biological Crystallization, Granada, Spain, 24-29 May.

To.Sca.Lake: Total Scattering Analysis of Naoscaled Materials, Como, Italy, 25-28 May.

Engineering Crystallography: From Molecules to Crystal to Functional Form, Erice, Italy, 5-14 June.

Sagamore XVIII Conference on Charge, Spin and Momentum Densities, Sardinia, Italy, 7-12 June.

Zürich School of Crystallography 2015: Bring Your Own Crystals, Zürich, Switzerland, 7-20 June.

22nd International Conference on the Chemistry of the Organic Solid State (ICCOSS XXII), Niigata, Japan, 12-17 July.

Second Balkan School on Fundamental Crystallography and Workshop on Magnetic Symmetry and Its Application in Magnetic Structure Description, Marmaris, Turkey, 1319 July.

2nd AONSA Asia Oceania Conference on Neutron Scattering (AOCNS-2015), Sydney, Australia, 19-23 July.

Electron Diffraction for Quantitative Surface Structure Determination, Lodz, Poland, 19-26 July.

Annual Meeting of the American Crystallographic Association, Philadelphia, USA, 25-29 July.

I Peruvian Congress of Crystallography and Course on Methods of Analysis of Polycrystals by X-ray Diffraction, Lima, Peru, 4-6 August.

Indaba 8, Kruger National Park, South Africa, 16-21 August.

16th International Conference on X-ray Absorption Fine Structure (IXAS-16), Karlsruhe, Germany, 23-28 August.

29th European Crystallographic Meeting - ECM29, Rovinj, Croatia, 23-28 August.

Electron Crystallography School - ECS2015, Rovinj, Croatia, 28-31 August.

ECNS 2015 VI European Conference on Neutron Scattering, Zaragoza, Spain, 30 August - 4 September.

2nd European Crystallography School (ECS2), Mieres, Spain, 31 August - 5 September.

Aperiodic 2015, Prague, Czech Republic, 1-6 September. 
European School on Crystal Growth/Fifth European Conference on Crystal Growth, Bologna, Italy, 5-8 and 9-11 September.

22nd Brazilian Crystallographic Association (ABCr) Meeting and II Latin-American Crystallographic Association (LACA) Meeting, Sao Paulo, Brazil, 9-11 September.

8th European Conference on Mineralogy and Spectroscopy (ECMS 2015), Rome, Italy, 9-11 September.

9th AOFSRR Cheiron School, Hyogo, Japan, 10-19 September.

2015 High Pressure Workshop, Campinas, Brazil, 11-15 September.

13th School on Synchrotron Radiation, Grado, Italy, 14-25 September.

XXIII Conference on Applied Crystallography, Krynica Zdroj, Poland, 20-24 September.

Size-Strain VII, Oxford, UK, 21-24 September.

International School on Introduction to the Rietveld

Refinement, Sofia, Bulgaria, 28 September - 3 October.

Workshop on Powder Diffraction of Organic Compounds,

Frankfurt/Main, Germany, 6-8 October.

VII School of the Argentinian Crystallography Association,

La Plata/Buenos Aires, Argentina, 26 October - 3 November.

9th International Conference on Inelastic X-ray Scattering

(IXS 2015), Hsinchu, Taiwan, 23-27 November.

13th Conference of the Asian Crystallographic Association,

Kolkata, India, 5-8 December.

3rd School on Crystallization and Crystallography for Latin America (ECRISLA 2015), Florianópolis, Brazil, 7-11 and 14-18 December.

The Executive Committee met in Rovinj, Croatia, in August. The Finance Committee met in Leuven, Belgium, in March and in Rovinj, Croatia, in August, to prepare its advice and recommendations on finances, establishment and staff matters.

The most important items of business dealt with by the Executive Committee at its meetings, and in e-mail ballots, were:

editorial policy, pricing policy and subscription rates, approval of appointments of Editors and Co-editors, progress of IUCrJ, journals development, review of subtitles for Acta journals, Special Issues, open access, and other matters concerning the IUCr journals;

review of contract with Wiley for IUCr journals;

launch of IUCrData;

International Year of Crystallography (IYCr) Closing

Ceremony, IYCr 2014 Legacy Resolution; IUCr-UNESCO

OpenLabs, establishment of Outreach and Education Fund;

approval of audited accounts for the previous year;

General Fund estimates and level of unit contribution;

status of membership subscriptions;

guidelines for countries wishing to become members of the

IUCr;

applications for membership;

proposal to introduce an IUCr Associates Programme;

investment policy; funding and uses of Publications and Journals Development

Fund and Research and Education Fund;

sponsorship and financial support for meetings, young scientists' support, Visiting Professorship Scheme, gender

balance of programmes;

inter-regional bursary scheme;

cooperation with databases, Diffraction Data Deposition

Working Group;

progress with Volumes A, A1, B, C, D, E, F, G, H and I of

International Tables and development of associated software;

IUCr Newsletter;

World Database of Crystallographers;

Online Dictionary of Crystallography;

promotional activities;

establishment of Ewald Prize Selection Committee;

discussion of arrangements for Hyderabad Congress.

Other items dealt with in this way were:

uses of the Crystallographic Information Framework (CIF),

work of the Committee for the Maintenance of the CIF

Standard (COMCIFS), provision of checking services to other publishers;

consideration of publications, jointly with Oxford Univer-

sity Press, in the IUCr/OUP Book Series;

crystallography in developing regions; Crystallography in

Africa;

review of activities of Commissions, formation of new

Commissions;

review of nomination procedures for Chairs and members

of Commissions;

review of activities of Regional Associates;

review of reports of IUCr Representatives on other bodies.

Items concerning the Chester office were:

staffing requirements in the IUCr office in Chester, appointment of Outreach Officer;

office premises;

risk analysis;

upgrading of office technology.

\section{Publications}

Volume 71 of Acta Crystallographica, Volume 48 of Journal of Applied Crystallography (JAC), Volume 23 of Journal of Synchrotron Radiation (JSR) and Volume 2 of IUCrJ were published.

\section{Adhering Bodies}

A list of Adhering Bodies of the Union, with names and addresses of the Secretaries of the National Committees for Crystallography, was published as Appendix D to the Report of the Twenty-Third General Assembly and International Congress of Crystallography [Acta Cryst. (2016), A72, 85167]. 


\section{Work of the Commissions}

\subsection{Commission on Journals}

\subsubsection{IUCrI}

$I U C r J$ had an excellent second year and has continued to establish itself within the wider scientific communities that use results obtained from diffraction methods. All the indications are good in terms of the journal making a strong impact in attracting high-quality science papers of wide scientific significance from these communities. Impressions from authors, readers, referees and commentators are very positive with a number of papers receiving high downloads in line with high-impact publications.

The journal is now included in the Science Citation Index and will receive its first impact factor (for 2015) in mid-2016. All indications are that the impact factor will be at a good level for such a newly launched journal. All submissions undergo preliminary screening by a panel consisting of the five Main Editors (Ted Baker, Richard Catlow, Gautam Desiraju, Sine Larsen, John Spence) and the Editor-in-Chief (Samar Hasnain), and this has helped to provide a rapid and efficient review process. Preliminary screening is generally complete within 72 hours, and any articles that do not meet the journal's requirement for broad scientific significance are usually transferred, with the agreement of the authors, to one of our other journals. Such transfers are seamless and do not require any further work by the authors.

The six issues of $I U C r J$ published in 2015 have featured papers from a wide variety of areas including biology, chemistry, crystal engineering, materials, physics and free-electron lasers (FELs). The number of articles submitted to the journal was 82 ; a total of 81 papers were published with an average turnaround time of 15 weeks. Articles have been highlighted by a number of different methods, with 12 highlighted via indepth commentaries.

The Biology and Medicine section of the journal has published about 50 papers so far. These have given us glimpses into an exciting future, in which complementary approaches will substantially widen the reach of structural biology. Primary among these are the new advances in cryo-electron microscopy (cryoEM) and the growing applications of FELs. Both approaches have a natural home in this journal, and to develop our coverage of cryoEM, we welcomed Richard Henderson to the Editorial Advisory Board, and Sriram Subramaniam and Werner Kühlbrandt as Co-editors.

In the Chemistry and Crystal Engineering section a large number of submissions have been received; we have published 55 papers in this section since the inception of the journal. The crystal-engineering papers are of a high quality and the community feels the journal is doing well relative to competitors. Papers submitted in the MOFs area are also of good quality. We expect more papers of general chemical interest to be submitted as researchers become familiar with the broader scope of the journal.

The other sections of the journal, covering Materials and Computation, Neutron and Synchrotron Science and Technology, and Physics and Free Electron Laser Science and
Technology have published 29, 21 and 29 papers, respectively, and have illustrated the rapid advances that are being made in these fields.

Dmitri Argyriou, former Science Director of the European Spallation Source, was appointed to succeed Sine Larsen on her retirement in July 2016. The Board and the Union express their gratitude to Sine for playing an active role in helping establish the journal.

Throughout 2016 we plan to encourage a greater number of papers reporting advances in technologies and methods that underpin our structural science. In addition to advances associated with synchrotron sources and X-ray free-electron lasers, we look forward to reporting major advances that are taking place in neutron sources, methods and applications.

In 2016, we will be present at a number of major meetings. Please come and visit the IUCr Journals stand, meet the Editors and become involved in making IUCrJ one of the mainstream comprehensive science journals. We look forward to seeing you there.

S. S. Hasnain, Editor-in-Chief, and D. Argyriou, E. N. Baker, G. R. Desiraju, C. R. A. Catlow, S. Larsen and J. C. H. Spence, Editors

\subsubsection{Acta Crystallographica Section A}

The first issue of 2015 started with the Editorial Celebrating the Past, Looking to the Future. In this we reiterated our plans for Acta A, explaining the aims of the new Advances section and emphasizing the fact that we are adopting higher standards for acceptance of articles across the board. In particular, beyond just describing a development, it is our aim that each article should identify the rationale for making the development and how it would be used by the crystallographic community.

Eight Advances papers were published during 2015: SHELXT - Integrated Space-Group and Crystal-Structure Determination (G. M. Sheldrick); Nuclear-Weighted X-ray Maximum Entropy Method - NXMEM (Christensen et al.); Diffuse Multiple Scattering (Nisbet et al.); Partial Order Among the 14 Bravais Types of Lattices: Basics and Applications (H. Grimmer); Identification of Inversion Domains in $\mathrm{KTiOPO}_{4}$ via Resonant $X$-ray Diffraction (Fabrizi et al.); Interpretation of Angular Symmetries in Electron Nanodiffraction Patterns from Thin Amorphous Specimens (Liu et al.); Solution of the Phase Problem at Non-Atomic Resolution by the Phantom Derivative Method (C. Giacovazzo); and Complex Modeling: a Strategy and Software Program for Combining Multiple Information Sources to Solve Ill-Posed Structure and Nanostructure Inverse Problems (Juhás et al.). These give a feel for the breadth of topics covered by the journal.

We also published a Feature Article on MicroED Data Collection and Processing (J. Hattne et al.), which was highlighted in the Scientific Commentary Accessible Atomic Structures from Sub-Micron Protein Crystals by J. A. Rodriguez. Howard Flack explained the utility of Grimmer's 
approach to order among the Bravais lattices in his Commentary The Revival of the Bravais Lattice. A Lead Article on Computation in Electron Microscopy by E. J. Kirkland was also made available online by the end of year as part of the January 2016 issue.

Several articles were highlighted on the new web page for Acta $A$, some with accompanying news items (written for a more general audience) on the IUCr home page. Our press releases were appreciated by authors and their institutions alike, and were picked up by several other publications. The number of people following us on Twitter also increased during the year.

A Special Issue on 100 Years of the Debye Scattering Equation, following the conference of the same name held in Trentino, Italy, 14-18 June 2015, is in preparation for 2016.

We would like to thank all our Co-editors for the time and effort that they devote to the journal, and in particular Vaclav Petricek, who retired from the Editorial Board during the year.

\section{S. J. L. Billinge and J. Miao, Editors}

\subsubsection{Acta Crystallographica Section B}

During 2015 the journal published a Special Issue on Energy Materials with Guest Editors Simon Parsons, Richard Walton and Karena Chapman. This was the third in the current series of Special Issues following the publication in 2014 of one on Crystal Engineering (Guest Editor Andrew Bond) and another on Non-Ambient Crystallography (Guest Editors Dave Billing and Andrzej Katrusiak). By the end of 2015, a fourth Special Issue on Crystal Structure Prediction (Guest Editors Graeme Day and Carl Henrik Görbitz) was underway and an associated 'must-cite' article on the Cambridge Structural Database was anticipated. Special Issues form a crucial part of our strategy to promote the message of the widened scope of the journal. They were largely responsible for a $64 \%$ increase in the number of full articles published from 66 in 2013 to 102 in 2014 (the number of pages published rose from 633 to 1036). Interestingly, although we only published one Special Issue in 2015, resulting in fewer articles and pages than 2014, the number of submissions to the journal actually rose from 126 in 2014 to 154 in 2015. All Special Issues require substantial time and effort on the part of the Guest Editors and we are extremely grateful to them for all their work. Further Special Issues are underway for 2016-2017, including Minerals and Related Materials (Guest Editors Sergey Krivovichev, Stuart Mills and Janusz Lipkowski) and Ferroelectric and Multiferroic Materials (Guest Editors include Pierre Bordet) and Halogen Bonding (Guest Editors Pierangelo Metrangolo and Mate Erdelyi).

In 2014 the journal introduced a new category of article, the Research Perspective, where the main or sole author is an established leader in a particular field and such articles are expected to review the development of that field, with a strong focus on the author's own contributions to its development. The journal will normally publish a maximum of one article in this category per annum. We are currently assessing proposals for the next Research Perspective.

The journal published five Feature Articles in 2015: Synergy Between Transmission Electron Microscopy and Powder Diffraction: Application to Modulated Structures (Batuk et al.); Pressure-Induced Structural Phase Transformation in Cobalt(II) Dicyanide (Yakovenko et al.); Aperiodic Crystals and Beyond (Grimm); Charge Density and Optical Properties of Multicomponent Crystals Containing Active Pharmaceutical Ingredients or Their Analogues (Gryl); Structural Studies of Metal-Organic Frameworks under High Pressure (McKellar \& Moggach). We continue to target prominent conference speakers as possible authors of these articles.

Commentaries (five in 2015) on some exceptional articles are now appearing more regularly at the front of the journal, and other articles have been highlighted by means of regular news features on the IUCr home page. In common with other IUCr journals, the home page for Acta $B$ was redesigned in 2015, allowing more extensive coverage of recent news items and highlighting of outstanding articles and the most cited papers from the journal. We continue to look for new and better ways to promote these outstanding contributions.

We have initiated a new category of article, the Opinion piece, where we invite an author to tackle possibly controversial topics: in 2015 Christer Aakeröy (Kansas State University, USA) asked Is There Any Point in Making CoCrystals? We have invited Birger Dittrich (Göttingen, Germany) to write on Are Charge Density Experiments Still Worth Doing? and Peter Stephens (Stony Brook, USA) on Can We Trust Powder Diffraction? We hope this type of article will stimulate debate and attract attention.

Acta $B$ is well established as a publication route for work in fields such as high-pressure crystallography and aperiodic structures, and we are working to expand our coverage, including crystal engineering and materials science. The journal will be represented at a number of scientific meetings in 2016, including the 66th Annual American Crystallographic Association meeting in Denver, USA, and the 30th European Crystallographic Meeting in Basel (Switzerland).

We are delighted to welcome Dr Francesca Fabbiani (Göttingen, Germany) to the Acta B board: Francesca brings expertise in areas such as high-pressure science, crystal growth and solid-state polymorphism. Andrew Bond (Cambridge, UK) has recently retired as a Co-editor and we thank him for his many contributions to Acta B, not least for being Guest Editor for our Special Issue on Crystal Engineering. Other Coeditors are due to retire by the end of the triennium and the important task of covering their areas of expertise and expanding into new areas is underway.

\section{A. J. Blake and M. de Boissieu, Editors}

\subsubsection{Acta Crystallographica Section C}

As part of our ongoing attempts to raise the prominence of Acta $C$, we published two key papers early in 2015: the SHELXL and PLATON papers, which are well read and will 
be highly cited. We anticipate that this should provide a temporary big boost to the impact factor, starting in 2017, and will help attract better papers and maybe kick-start the journal into the format it is striving to have. A similar paper highlighting the CRYSTALS software has just appeared in the journal (April 2016). The editorial on the Coordination Polymers Virtual Issue (mid-2014) is highly read, which suggests that perhaps a good editorial or comment/brief review on the right topics might attract attention, although it might not be cited so often.

Recently, the long-awaited review panel was inaugurated with over 60 members. The availability to Co-editors of people who have committed to review papers regularly should alleviate some of the difficulties experienced over recent years in finding expert reviewers who respond promptly. The current team of Co-editors is working very well and we are most appreciative of their efforts.

As usual, we are very grateful for the energy and contributions of all Chester staff. The Managing Editor recently started adding relevance-related statements to the abstracts during paper preparation by taking appropriate sentences from the paper introduction. Authors seem happy with that approach and it is working better than past attempts at requiring authors to include such statements in the abstracts themselves.

Unfortunately, the impact factor decreased in 2015, despite the three Special Issues at the end of 2013, which should have had the opposite effect. The average number of submissions each month is still in decline and measures are needed to boost submissions. Our rejection rate remains around 50\%, because many submitted papers are still brief and more suited to Acta $E$. This is a pattern that has been ongoing ever since the inception of Acta E. The new style of Acta E is now more suited to the sorts of papers Acta $C$ once used to publish, which means that we need to attract fuller chemistry-related papers. We are receiving fewer papers that are suitable for the journal, and even fewer that properly fit the remit of what we ideally wish the journal to be publishing. There is a slight trend towards the papers containing more chemistry, and certainly the average length of Acta $C$ papers has increased slightly, but we need papers that present much more than experimental synthesis details and then analyses of the presented structures. On the other side, we are trying to be more like Acta B, with just a different focus area, but in some ways this may be limiting what Acta $C$ can do and a few papers that have appeared in Acta B could equally well have fitted into Acta $C$.

The journal will continue to publish Special Issues. The NMR crystallography special issue has taken longer to get going than we had hoped, but now seems to be well on the way and we expect to publish it this year. Despite the delay, the Special Issue will be important as a lot of interest has developed in this field in the meantime. We will also have another Special Issue on scorpionates later this year, to celebrate a golden anniversary in this field; Glenn Yap suggested this and is the Guest Editor.

Some ideas for other Special Issues met with frustrations at finding a Guest Editor. Maybe IUCr Journals has to consider if the current modality of handling of papers, in particular Special Issue papers, is consistent with current practices in an era where the essentially volunteer Guest Editors and Coeditors we rely upon have many more constraints on their time than perhaps 20 years ago. This is important as most prominent people are very busy and are unwilling to take on even more work. Related to this, we think it is asking a lot these days if we expect a journal to have fewer Co-editors who handle more papers.

In summary, we feel it is our responsibility to indicate that the journal still seems to be in decline and that the measures put in place over the last few years do not appear to have yielded much fruit so far. We will need to wait and see if the expected impact factor increase attracts more papers of the type we need in Acta $C$.

\section{A. Linden and P. R. Raithby, Editors}

\subsubsection{Acta Crystallographica Section D}

As anticipated, the Acta $D$ impact factor has dropped over the past few years; this metric was artificially high due to a few exceptionally highly cited methods papers a few years ago. The number of submissions to Acta $D$ appears to be correlated with the impact factor, though with a year or so delay. At the 2015 meeting of the Journals Management Board, we discussed the flawed metric of impact factor, recommending that we use median not mean, but we recognise that a universal change to the median is out of our control.

Notwithstanding, we have been working to increase the impact of the journal by expanding the scope - with a concomitant change in name (to Acta D Structural Biology from Acta D Biological Crystallography). In terms of the expanded scope, in 2015 we published a CCP4 Proceedings on complementary methods that included papers on SAXS, sometimes in combination with fibre diffraction or DEER spectroscopy, and a paper describing the structural results of sub-tomogram averaging. We wrote an editorial that highlighted the new scope (published in the January 2016 issue), developed a workflow summary for Co-editors, and have been working closely with Acta F Section Editors to streamline the protocol and processes for transferring between the journals.

The rejection rate of papers has stabilized to a little under a third of papers, which we consider to be a reasonable cut-off. Short Communications have dropped off as we have eliminated this category.

Pleasingly, the proportion of open-access papers (an authorselected option requiring an additional payment) has increased considerably over the past few years. The percentages in 2010-2012 were relatively static at about $1 / 5$ of accepted papers $(20-22 \%)$; this rose to $28 \%$ in $2013,34 \%$ in 2014 and $35 \%$ in $2015-$ i.e. now over $1 / 3$ of papers published in Acta $D$ are open access.

The average publication time for Acta $D$ remains steady at $\sim 5$ months, and this is in large part due to factors outside of our control (time required for authors to revise, time required for reviewers to provide their comments). 
Our final comment focuses on editor diversity. While the excellent panel of Acta D Co-editors represents the span of expertise and geography in our community, we are disappointed that the historic gender imbalance of editors in our sub-discipline remains stubbornly in place (despite our subdiscipline having a long history of high-profile women researchers). In our view, it is an urgent priority to re-evaluate the policies and procedures underlying Co-editor appointments, to address this imbalance.

\section{Z. Dauter, J. L. Martin, R. J. Read and S. Wakatsuki, Editors}

\subsubsection{Acta Crystallographica Section E}

2015 saw the completion of the transformation of Acta E from Structure Reports Online to Crystallographic Communications. The subtitle was changed in January and the final Data Reports were published in the December issue. The average number of Research Communications published each month rose by $20 \%$ compared to 2014 with a total of 395 published in 2015. The average length of a Research Communication also increased (from 3.7 pages in 2014 to 3.9 pages in 2015). We were pleased to see that papers reporting two or more structures are a now regular feature and that more authors are choosing to discuss complementary techniques, making the most of the opportunity to include extra tables and figures in the published paper to illustrate their results and enhance the discussion of the underlying science. We have also noticed the Research Communications format is attracting new authors to the journal and that the range of structures is far broader. The change in subject matter is reflected by the far higher proportion of metal-organic $(39 \%)$ and inorganic (10\%) papers compared to Data Reports, where the proportion of organic (80\%), metal-organic $(19 \%)$ and inorganic $(1 \%)$ papers is much the same as in recent years.

A total of 768 Data Reports papers were published in 2015, down from 1165 the previous year. From January 2016, Data Reports have found a new home in the IUCr's innovative open-access data publication, IUCrData. Publication times still remain low with an average submission-to-publication time of 0.8 months.

Although there was a further fall in submissions from 1478 in 2014 to 1273 in 2015, for the first time since 2011 the number of pages published increased compared to the previous year. The total of 2931 was up $25 \%$ on 2014 (2351 pages). As for last year, authors from more than 70 countries continue to publish with Acta E. The six top contributors in 2015 were India (19.7\%), USA (11.9\%), Germany (7.7\%), People's Republic of China (7.2\%), South Korea (5.4\%) and Japan (5.1\%). It will be interesting to see how this profile changes in 2016 when only Research Communications are included.

One of the stated aims of the relaunch of Acta E has been to regain indexing in the Science Citation Index. We are therefore delighted that the journal was included in Thomson Reuters' new Emerging Sources Citation Index (ESCI) when it launched in November 2015. This means that articles published in
Acta E can now be found in searches of the Science Citation Index. Importantly, it also means the journal is under consideration for inclusion in the Science Citation Index Expanded. We hope that the final phase of the transformation of Acta $E$ outlined above will herald the early re-indexing of the journal.

The pre-review system, whereby the Section Editors preview the submissions to consider the quality of the paper and make sure that it is in the appropriate format, is working well. The system was updated at the end of the year so that the Section Editors now decide if a submission should be published as a Research Communication in Acta E or if it should be transferred, subject to the agreement of the authors, to IUCrData. Often authors wish to see their work published as a Research Communication rather than as a Data Report. In such cases the Section Editors will advise authors on the changes needed to bring their submission up to the required standard, prior to a full assessment in the usual way by a Coeditor. The introduction of a new version of publCIF has made it easy for authors to prepare both types of publication and we must put more emphasis on the use of this software and its functionality to generate the correct format for the submission.

A large part of the success of the new Research Communication and IUCrData formats is down to our dedicated team of Co-editors who are doing an excellent job in advising authors how to promote their science. The Section Editors of Acta $E$ would like to take this opportunity to thank them for helping make Acta Crystallographica Section E Crystallographic Communications the obvious choice for disseminating the results of the excellent crystallography that is being carried out by our authors worldwide. Matias LópezRodríguez and Uk Lee retired as Co-editors during the year, and it is our pleasure to record here our sincere appreciation of their sustained outstanding efforts and their support of the journal.

An Advisory Board was established in 2014 and we appreciate and thank the various members for their continued confidence and support. We are also extremely grateful to the Chester Editorial Office staff for their dedicated support and contributions to the ongoing daily operations of the journal.

W. T. A. Harrison, H. Stoeckli-Evans, E. R. T. Tiekink, L. Van Meervelt and M. Weil, Editors

\subsubsection{Acta Crystallographica Section F}

Our overarching aim is to make Acta $F$ a highly visible journal for speedy publication of structural biology communications. In an editorial published in December 2014, new guidelines for manuscripts were announced, designed to increase the information content of our papers, to make them more useful to Acta $F$ readers and to our community as a whole. This editorial was accompanied by an e-mail to all Co-editors informing and alerting them of the new guidelines. As a consequence, 2015, Section F's eleventh year of publication, has seen a reduction in the number of submitted manuscripts 
by about $20 \%$. At the same time, the rejection rate has more than doubled and is now the second highest of all IUCr journals. Taken together, the number of published articles is at a record low at 251 . Because the average paper length increased by about $20 \%$ compared to 2014 , the number of pages published is, however, only down by $10 \%$ compared to the previous year. Despite the submissions all being more detailed, our average publication time has remained steady at around 3 months, owing to the combination of excellent contributions from our reviewers including the members of our review board, the diligence of the editorial board and, of course, staff at the Chester office. We are also pleased to record an increase in the relative percentage of open-access papers, a factor important for visibility, and one in which we hope to improve on further.

Somewhat disappointing has been the limited progress in obtaining review articles or in producing Special Issues where it has proved difficult to identify Special Issue Editors. For the future then, this is an area in which we need to consider how best to improve engagement with our community. In terms of citations, although the cited half-life of the papers published in Acta $F$ is slowly creeping up, the impact factor remains below 1.0, which has been the target we set a few years ago. We are confident, however, that with the new enhanced content of our manuscripts, we are addressing this issue as well.

A very welcome development has been the successful appointment of Zbyszek Dauter as an additional Section Editor for Acta F. Zbyszek is a very well known and respected crystallographer who has previously been one of the Section Editors of Acta D. He will undoubtedly enrich our journal with his experience and provide the necessary editorial input from the North American side.

\section{S. Weiss and W. N. Hunter, Editors}

\subsubsection{Journal of Applied Crystallography}

From the beginning of 2014, in common with all IUCr journals, $J A C$ became online only. As a result a number of changes in the format have been developed, more appropriate to an online journal. For example, each online issue now generally has its own cover illustration - taken from a highlighted or other major paper within the issue. Highlighting of articles, and the appearance of Features and Commentaries, are other new aspects developed during 2015.

While the number of published articles decreased slightly in 2015 , it is clear that $J A C$ continues to focus on the application of crystallography and crystallographic methods in all their forms (other than crystal structure determinations), and on the instrumentation, techniques and other factors involved. As stated in the journal's expanded scope statement, we continue to welcome many research topics in condensed-matter research, materials science and the life sciences that make use of crystallographic methods to study crystalline and noncrystalline matter with neutrons, X-rays and electrons. All of these areas were reflected in the journal's papers during 2015. Developments of instrumentation and crystallographic appa- ratus, theory and interpretation, numerical analysis, computer programs and Teaching and Education papers also continue to have presence. We note that the journal remains the primary place where crystallographic computer program information is published and some clarification has recently been provided in the Notes for Authors as to what is expected of authors of Computer Program papers, including independent reports on the software itself.

We note that the latest impact factor of 3.98 , published in 2015 for 2014, remains among the highest for crystallographic journals. Echoing a point made last year, we would welcome more high-quality papers focusing on industrial applications of crystallography. During 2015, some new Co-editors were appointed to replace expertise lost with retiring Co-editors, and to extend our expertise into new areas of applied crystallography.

Although $J A C$ no longer publishes conventional Conference Proceedings as Special Issues, 2015 did see the publication of a new Special Issue containing select full-length research papers associated with the 12th Biennial Conference on High-Resolution X-ray Diffraction and Imaging (XTOP2014), and others are planned both centred on technical themes (e.g. FEL Software, expected summer 2016) and associated with prominent conferences such as the 16th International Conference on Small-Angle Scattering (SAS2015), expected summer/autumn 2016.

During 2015, the $J A C$ arrangement with three Main Editors to provide greater efficiency in all editorial matters pertinent to the long-term health of the journal has worked well. While regular paper submissions are not pre-selected (i.e. prior to assignment to a Co-editor), the option remains for the Main Editors to start pre-selecting papers for their suitability if circumstances require this in the future.

Special Issues, highlighting of papers, invited Commentaries (citable themselves with included relevant references) and Feature Articles have all seen some development and evolution during 2015. Commentaries are solicited from authors other than the authors of the paper being highlighted, at the discretion of the Main Editors.

$J A C$ continues to welcome a small but strategically important category of papers in the area of Teaching and Education, and Juan Manuel García-Ruiz welcomes such papers as our Teaching and Education Co-editor.

We note that $J A C$ remains a hybrid journal. Authors of accepted papers have the option to retain access to their paper based on journal subscription, or to secure open access to their paper on payment of a charge to the IUCr Editorial Office. The cost per article of open access for a paper published in $J A C$ (or any other IUCr journal) remains significantly less than that for articles published in most other journals of comparable impact. In 2015, open-access papers have tripled in proportion and now account for about $15 \%$ of the total papers published.

Many challenges lie ahead for scientific publishing, especially with regard to subscription-based access versus open access, the growing demand to archive and provide access to research data, and the general demands placed on increasingly 
busy reviewers to provide the core support for a fair and rigorous review system. However, we believe that $J A C$ is well placed to meet the challenges ahead.

\section{A. J. Allen, J. Hajdu and A. R. Kaysser-Pyzalla, Editors}

\subsubsection{Journal of Synchrotron Radiation}

2015 saw a large increase in the number of papers published in $J S R$ and hence also in the number of pages published. A total of 210 papers were published in 2015 (187 in 2014), amounting to 1560 pages (1385 in 2014). The number of submissions decreased slightly to 258 compared with last year's total of 262 . The rejection rate also decreased for a second year, down from $22 \%$ to $19 \%$, and publication times came down from 5.4 to 5.1 months. Two Lead Articles and two Feature Articles were published in 2015, as well as one Scientific Commentary. The number of Beamline papers published increased to 15 (from 12).

Two new Main Editors were also appointed to the journal during 2015. Firstly, Mikael Eriksson, an accelerator physics expert from MAX IV in Sweden who was one of the Guest Editors of the Diffraction-Limited Storage Rings Special Issue published in September 2014. With many SR sources undergoing upgrade it is hoped that Mikael will attract advances in the field. Secondly, Yoshiyuki Amemiya from the University of Tokyo, Japan. Yoshiyuki was one of the founding Coeditors of $J S R$. He is heavily involved with the Photon Factory and SPring-8 and its free-electron laser SACLA. This gives $J S R$ five Main Editors, one specialized in FELs, one in accelerators and three representing the science communities from Europe, USA and Japan.

Two Special Issues were published in JSR in 2015. The March issue included papers from the the X-ray Radiation Damage to Biological Crystalline Samples Workshop, with Guest Editors Elspeth Garman and Martin Weik. The number of Special Issue pages totalled 85 from 9 papers. The May issue contained Special Issue papers on X-ray Free-Electron Lasers, organized by Main Editor Ilme Schlichting, Co-editor Makina Yabashi and Guest Editor Bill White. Here the number of Special Issue pages was 182 from 27 papers.

On the subject of free-electron lasers (FELs) and the ability of $J S R$ to attract papers from the FEL community, the number of papers published on this topic has risen steeply over the past few years. This has been partly due to the appearance of the aforementioned XFELs Special Issue. Since 2013 the percentage of FEL papers published in $J S R$ has been $11 \%$ and it would be useful to increase this number and help to attract new readers and authors, particularly in light of the number of FELs currently under development. Recent appointments over the last two years to the JSR Editorial Board will hopefully help to attract such papers.

We thank the readers of $J S R$ for their continued interest and support, the authors for publishing in our journal, the Co-editors for their great services to the community, and the Managing Editor, Tony Weight, for running the journal like clockwork. Thanks are also due to the Editor-in-Chief,
Samar Hasnain, for his continued support of the journal's activities.

Y. Amemiya, M. Eriksson, G. E. Ice, I. Schlichting and J. F. van der Veen, Editors

\subsection{Commission on International Tables}

International Tables for Crystallography is a book series published by the IUCr in conjunction with Wiley. Eight volumes designated A (and A1) through $G$ are currently in print, a ninth ( $\mathrm{H}$, on powder diffraction) is nearly done, and a tenth (I, on XAFS) is being written. Printed volumes can be purchased individually; online access is by subscription to the entire series. A low-cost print edition of the Brief Teaching Edition of Volume A (Space-Group Symmetry) is also available.

Sales of the print editions have been declining rapidly over the last few years (in common with print sales for many other major reference works), but sales of access to International Tables Online remain strong. Several of the volumes in the series now contain or plan to include content that is or will be available only in the online version.

Descriptions of activities during 2015 for the individual volumes follow.

Volume A (Space-Group Symmetry). Final work on the preparation of the 6 th edition of Volume A continued through 2015 but there have been delays. The typesetting of the tables and text have been completed but proof-reading continues and a few nomenclature issues are still being resolved. Nevertheless, in January 2016 the first three chapters of the new edition were made available on the web site of International Tables for Crystallography. The printed edition is expected to appear during the summer of 2016.

Symmetry Database server of the Online Edition of International Tables. The work on the enhancement of the Symmetry Database of the Online Edition of International Tables for Crystallography continued through 2015 within the framework of a new project between the IUCr and the software company eFaber (Bilbao) under the supervision of M. I. Aroyo. The main activities focused on the extension of the crystallographic data available online and the development of interactive visualizations for the point-group symmetries. The space-group data were extended to include the site-symmetry groups, the geometric interpretation of the symmetry operations and their Seitz symbols. The necessary databases and algorithms for the corresponding computational tools were provided by the Bilbao Crystallographic Server team. The interactive visualization tools of the crystallographic point groups have been developed by a research group at the Universitat Autónoma de Barcelona. Prototype html versions of the visualization tools for several point groups are already accessible online.

Brief Teaching Edition of Volume A (BTE). Most of the text and tabular material for the Brief Teaching Edition of Volume $\mathrm{A}$ is in an advanced state of preparation. The development of 
the Brief Teaching Edition has been held up by delays in the publication of the 6th edition of Volume A, on which it is based. The typesetting of the material for the Brief Teaching Edition is expected to start during the second half of 2016.

Volume B (Reciprocal Space). Discussions have continued about the reorganization of Volumes $\mathrm{B}$ and $\mathrm{C}$ to give a more sensible grouping of topics. All chapters related to incommensurate crystallography will be in the new Volume B, which will also cover dual-space refinements, charge flipping and fast Fourier transforms. Discussion about adding a second Main Editor led to the appointment in early 2016 of Michal Dusek, who agreed to take on that role.

Volume C (Mathematical, Physical and Chemical Tables). During 2015 work towards the new Volume C progressed steadily. Authors have been found for a substantial list of topics including both 16 completely new topics and revisions and updates of eight current ones. Writing is in progress on many of these and the first completed articles should be ready soon. The Editorial Office have set up a submission site in Chester. A newsletter has been started to keep the authors informed of progress on the volume as a whole.

Some of the current chapters/sections may be retained with little need for revision. Some, however, have become largely redundant because the material is either out of date or is covered in the new Volume H (Powder Diffraction) or in the new Volume A. The forthcoming Volume I (XAFS) will also render some current material superfluous.

Volume D (Physical Properties of Crystals). Some inaccuracies in one table of one chapter were brought to the attention of the Editor and will be corrected in the online version.

Volume E (Subperiodic Groups). The Seitz symbols in the print and online version of the 2 nd edition are not the kind that were later approved by the IUCr. Modification of these symbols in the online edition is planned for late 2016 or early 2017.

Volume $G$ (Definition and Exchange of Crystallographic Data). The revised table of contents and author list for the next edition of Volume $G$ was agreed on at a day-long editorial meeting in August 2015. Progress will depend on the rate at which individual CIF dictionaries can be represented using the new dictionary language standard, which will require the approval of the relevant dictionary management groups.

Volume $H$ (Powder Diffraction). The proofs for seven chapters have been sent to the authors. 29 chapters are ready for typesetting, seven chapters are being updated by the authors, five chapters are in review, and seven chapters are still in preparation. Publication by the end of 2016 is still the goal.

Volume I (XAFS). All of the Commission on XAFS is assisting in creating this new volume under the direction of the three Main Editors. Individual contributions will be shorter than for most other volumes of International Tables; the staff in Chester have devised methods for working with this new model. Some 100-150 experts have accepted the invitations to write specific advanced chapters and 10 articles have been submitted. The reviewing process has begun.
A side benefit of this process has been the addition to the IUCr's Online Dictionary of a large number of terms related to the interests of the XAFS community.

Other volumes. Very preliminary discussions have begun about how Volumes A1 (Symmetry Relations Between Space Groups; 2011), F (Crystallography of Biological Macromolecules; 2012), and D (2014) might be revised. The Editors of Volumes A1 and D (Physical Properties of Crystals) are thinking about appointments of new Editors. It has been recognized that the field covered by Volume $\mathrm{F}$ is evolving so rapidly that a revision will be a major undertaking.

Further information about the volumes can be found at the home page of the Commission, http://www.iucr.org/resources/ commissions/international-tables. The Guided Tour available at http:/it.iucr.org/services/guidedtour/ is highly recommended because it shows what is available electronically. Access to the Tables of Contents of all the volumes is free, as are sample pages (including author lists and prefaces); see the home pages for the individual volumes (e.g., http://it.iucr.org/ $\mathrm{Fb} /)$.

It is a pleasure to thank the staff in Chester, and especially Nicola Ashcroft, for all they do to help to maintain and expand this series. Their skill, professionalism and experience are invaluable.

It is not possible to end this report without noting the passing of Hans Wondratschek in October 2014 and Theo Hahn in February 2016. Theo Hahn chaired the Commission on International Tables in the periods 1972-1981 and 19932003. He edited five editions of Volume A, created its Brief Teaching Edition, and was involved with the 6th edition that will appear in 2016. Hans Wondratschek may be best known as the co-creator of Volume A1 but he was also very involved for many decades with Volume A and he contributed to Volume B. The contributions of Hahn and Wondratschek to the International Tables were enormous; their active involvement will be greatly missed.

\section{P. Brock, Chair}

\subsection{Commission on Aperiodic Crystals}

Following on from a very successful year with a great deal of publicity around aperiodic crystals, the Commission on Aperiodic Crystals (CAC) continued to promote aperiodic crystallography in 2015, by organizing, supporting and promoting scientific meetings, workshops and educational activities worldwide. In particular, CAC continued its ongoing coordination of interaction between the various subcommunities and disciplines involved in the different aspects of research in aperiodic crystals, as well as the dissemination of research results to the greater scientific community.

Our flagship scientific event in 2015 was the 8th International Conference on Aperiodic Crystals (Aperiodic 2015), which was held at the beautiful venue of the Brevnov Monastery in Prague, Czech Republic, 30 August - 4 
September 2015. The conference, which was chaired by Michal Dusek and Vaclav Petricek, is the eighth in the series of triennial conferences organized under the auspices of the CAC, this time with the Czech and Slovak Crystallographic Association as the local organizer. The conference was attended by 134 delegates from 25 countries, among them 22 young scientists who were supported by IUCr funding. In the five conference days, a broad range of topics, including classical modulated structures, quasicrystals and magnetic structures, symmetry aspects, mathematical aspects, tiling theory, high-pressure crystallography, diffuse scattering, lattice dynamics, physical properties, and commercial aspects were covered. The programme included the honorary lecture Usefulness and Unusefulness of the Superspace Approach to Aperiodic Crystals, given by the 2014 Ewald Prize winner Ted Janssen. A special session was devoted to the memory of Chris Henley, one of the pioneers of quasicrystal theory, who had sadly passed away on 29 June 2015. The Commission wishes to express its gratitude to Michal Dusek, Lukas Palatinus, Vaclav Petricek, Radek Kuzel, Jindrich Hasek and Jirina Pilna, as well as the entire team who made this event a success. For more details, see the conference web site at http://crysa.fzu.cz/ aperiodic2015/.

During Aperiodic 2015, a Commission meeting was held in Prague on 1 September, and the Commission enthusiastically supported the proposal to hold the next meeting in the USA, where it will be hosted for the first time. The 9th International Conference on Aperiodic Crystals will be held in 2018 in Ames, Iowa, organized by Alan Goldman, Gloria Borgstahl and Pat Thiel.

The Aperiodic 2015 conference followed on immediately from the 29th European Crystallography Meeting in Rovinj, Croatia, which took place 23-28 August. It featured a Keynote Lecture by Ron Lifshitz on quasicrystals in soft condensed matter as well as two Microsymposia dedicated to modulated crystals and quasicrystals.

Other events in 2015 that were supported by the CAC included the 8th Workshop on Structural Analysis of Aperiodic Crystals in Bayreuth, Germany, 12-15 March 2015 (http://aperiodic.uni-bayreuth.de/workshop_2015). This fourday workshop was organized by the Special Interest Group on Aperiodic Crystals (AK 16) of the German Crystallographic Association (DGK), with local organisers Andreas Schönleber and Sander van Smaalen. It attracted 29 participants, including 17 young scientists (mainly $\mathrm{PhD}$ students), from Czech Republic, France, Germany and Switzerland. Further events include a Jana workshop with 50 participants at the 6th Shanghai Workshop on X-ray Crystallography at the College of Materials Science and Engineering, Shanghai University, People's Republic of China, in April 2015, and the XXIII Conference on Applied Crystallography in Krynica Zdrój, Poland (http://www.cac.us.edu.pl/), which took place 20-24 September 2015. In addition, four ad hoc Jana2006 workshops with in total 49 participants were offered in 2015; see http:// jana.fzu.cz/ for details. On the mathematical side, there was a Workshop on Spectral Theory of Aperiodic Systems at the Heinrich-Fabri-Institut in Blaubeuren, Germany, in June, which was co-organized by the Chair of the Commission, and several further events, including a Workshop on Aperiodic Order at the University of Leicester, UK, in January, a Workshop on Time-Frequency Analysis and Aperiodic Order in Trondheim, Norway, in June, an Arbeitsgemeinschaft: Mathematical Quasicrystals at the Mathematisches Forschungsinstitut Oberwolfach, Germany, in October, and a Workshop on Geometry and Dynamics of Quasiperiodic Structures at the Institut Henri Poincaré in Paris, France, in December 2015, all of which the Chair attended.

The Commission is looking forward to exciting events in 2016 and in 2017. Planned activities include the 3rd International School on Aperiodic Crystals, which will be held in Antwerp, Belgium, in July 2016, and is organized by Joke Hadermann. It follows on from the successful schools in Carqueiranne, France, in 2010 and in Bayreuth, Germany, in 2013. This is our central educational activity, with the objective of providing an overview of aperiodic order, of the basics of the mathematical description of both modulated structures and quasicrystals, of physical properties and chemical understanding of aperiodic crystals, as well as a working knowledge of structural analysis of aperiodic crystals. The other important meeting to take place in 2016 is the 13th International Conference on Quasicrystals (ICQ13) in Katmandu, Nepal, in September 2016, which is being organized by Hem Raj Sharma and An Pang Tsai. The Commission has also been actively involved in shaping the programme for the forthcoming Hyderabad Congress, and we are hoping to contribute to an attractive and exciting programme.

\section{U. Grimm, Chair}

\subsection{Commission on Biological Macromolecules}

The aim of the Commission on Biological Macromolecules (CBM) is to support macromolecular crystallography worldwide through scientific exchange, training, and promotion of policies that encourage the generation and dissemination of knowledge and technologies.

Standards for information to be provided to reviewers of macromolecular structures. The CBM has continued to work with the American Crystallographic Association, the Asian Crystallographic Association, the European Crystallographic Association and the Worldwide Protein Data Bank (wwPDB) to begin the development of standards for information that reviewers of macromolecular structures should receive. The key ideas in these draft standards are that for a macromolecular crystal structure, reviewers should receive (1) the PDB validation report and (2) pictures of omit maps for any ligands and unusual structural elements. Additionally, the draft standards suggest the idea of making the data (structure factors, coordinates) available to reviewers. In 2015 CBM members were part of a wwPDB workshop further to develop standards for ligand validation. The results from this workshop were published in Structure [Outcome of the First 
wwPDB/CCDC/D3R Ligand Validation Workshop; Adams et al. (2016), Structure, 24, 502-408].

IUCr Diffraction Data Deposition Working Group $(D D D W G)$. The CBM has worked with the IUCr's DDDWG to evaluate theoretical and practical reasons for the deposition of raw diffraction images that constitute the primary data in a macromolecular X-ray diffraction experiment. During 2015 a workshop was held at the European Crystallographic Association Annual Meeting and CBM members made major contributions to the discussion. Major progress during 2015 included the implementation of a new public server where anyone can download many crystallographic raw datasets (https://www.youtube.com/watch?v=eQbs9sB_pOM). An extensive discussion of the issues is available on the DDDWG forums page at http://www.iucr.org/forums/dddwg.

Meetings, workshops and other outreach activities. The CBM has recommended support from the IUCr for a number of meetings and workshops that can provide a teaching or major dissemination role for macromolecular crystallography.

\section{T. Terwilliger, Chair}

\subsection{Commission on Charge, Spin and Momentum Densities}

The main event in 2015 was the XVIII Sagamore Conference, which is the only conference that covers all three subjects covered by the charge, spin and momentum density community. The meeting was organized by Carlo Gatti (past Commission Chair) and his colleagues and co-workers from the University of Milan and the CNR-ISTM of Milan. The venue was Santa Margherita di Pula, on the Italian island of Sardinia, on 6-12 June. The participation was very large and, as usual, the scientific talks were accompanied by long discussions, favoured by the pleasant atmosphere of the venue. The scientific programme encompassed various fields of electron density in life and materials science - in particular, new experimental probes and theoretical methods, chemical and crystal engineering, functional materials and nanoscale, structure evolution and densities, topological approaches, extreme conditions and biochemical applications.

The next Sagamore Meeting will be organized in 2019 in Canada and the Chair of the meeting will be Cherif Matta, in cooperation with Paul Ayers.

For the momentum density community, in 2015 another important event was organized and partially supported by the Commission, namely the 9th International Conference of Inelastic X-ray Scattering, held at the National Synchrotron Radiation Research Center in Hsinchu, Taiwan (22-26 November). The meeting programme included: Compton scattering and extreme conditions; energy materials; emergent two-dimensional materials; low-energy excitations of correlated electron systems; magnetism; molecules and liquids; time domains; and new frontiers of theory and experimental techniques.

The Commission has also organized and supported the 1st Asian Charge Density Workshop, held at the Indian Institute of Science in Bangalore, India, 22-25 February 2015, orga- nized by Professor Guru Row (Commission consultant) in collaboration with Commission member Louis Farrugia, from the University of Glasgow. The school covered the basic aspects of charge-density refinement and analysis, with handson tutorials using the most widely used programs, $M O-P R O$ and $X D$. The workshop was attended by more than 40 students, mainly from Asia. It was followed by a special session on charge density within the National Symposium on X-ray Diffraction and Recent Advances in Crystallography, organized by Professor Poomani Kumaradhas (Periyar University, Salem, India).

A workshop on charge-density determination was also held at the University of Minas Gerais, Belo Horizonte, Brazil, 31 August -4 September 2015, organized by B. Rodrigues, with lectures and tutorials. The Commission hopes that this will encourage the organization of the first charge-density workshop in South America in the near future.

During 2015, one of the two Commission projects, the round robin test on charge-density determination using synchrotron and home-laboratory radiation sources, made significant progress with data collected by all participants, following the protocol written by J. Overgaard and E. Espinosa. The project leader, Jacob Overgaard (University of Aarhus, Denmark), will analyse the data and produce a final report by the end of 2016.

In September 2015, Robert F. Stewart, one of the fathers of the multipolar model and initiator of many research activities in the field of charge density, unfortunately passed away. His contribution to the field was of enormous value and his thought-provoking activity was always fundamental during conferences. The Commission has decided to name a series of schools on charge density in his honour, the first of which will be held in Nancy, France, 23-26 August 2016, organized as a satellite of the 30th European Crystallographic Meeting (Basel, Switzerland, 28 August - 1 September 2016). Other Robert F. Stewart schools on electron density and related properties are expected in forthcoming years.

\section{P. Macchi, Chair}

\subsection{Commission on Crystal Growth and Characterization of Materials}

In 2015 the members of the Commission collaborated actively but mostly via the internet. However, in September, during the Fifth European Conference on Crystal Growth in Bologna, Italy, some of us (Koichi Kakimoto, Ewa Talik, Elias Vlieg, Thierry Duffar and myself) had the opportunity to meet in person and exchange opinions. The main points discussed were: (1) the future of crystal growth around the world; (2) the organization of the Hyderabad Congress; and (3) the status of the organization of the next International Conference on Crystal Growth, ICCGE-18.

In 2015 the Fifth European Conference on Crystal Growth and the First European School on Crystal Growth were held in Bologna, Italy. Many Commission members and consultants were involved in the organization of these events: for example, 
Elias Vlieg and myself as Chairs of the School and Conference respectively. It has been decided that both the European School and Conference will take place in 2018 in Bulgaria. We are very happy that the tradition of European Crystal Growth Conferences has been re-established and likewise the tradition of holding the European Schools on Crystal Growth.

In August 2017 there will be the IOCG Conference in Nagoya, Japan. Our Commission is involved at different levels in the organization of this important event, and more details are given in my report as IUCr Representative to the IOCG. Here it is important to underline that three Microsymposia of the IOCG Conference will be officially co-organized by representatives of the IUCr, namely Janakiraman Kumar (Defect Formation), François Puel (Industrial Crystallization) and Garcia Ruiz (Organic and Biological Crystallization).

In 2015 the IUCr supported the following schools/meetings that were important for the crystal-growth community:

Fifth European Conference on Crystal Growth (ECCG5), Bologna, Italy, 9-11 September 2015;

First European School on Crystal Growth 2015 (ESCG 2015) - Fundamentals of Crystal Growth;

5th International School on Biological Crystallization (ISBC2015), Granada, Spain, 24-25 May 2015;

48th edition of the International School of Crystallography, Erice, Italy, 5-14 June, 2015.

Finally, I wish to express my great honour and pleasure to continue to chair this Commission. I hope I am making my own contribution to all the work done up to now by the Commission to bring more understanding of the role of crystals and their influence on many aspects of life and technology.

\section{A. Zappettini, Chair}

\subsection{Commission on Crystallographic Computing}

The Commission is organizing a Computing School to be held at the Molecular Biophysics Unit of the Indian Institute of Science in Bangalore, India, during the week before the Hyderabad Congress, i.e. 15-20 August 2017. The local organizer is Professor B. Gopal of the Indian Institute of Science, Bangalore; he has also been appointed as a member of the INSA-ICSU Committee for the IUCr.

The School web site is hosted on the IUCr server at http://www.iucr.org/resources/commissions/crystallographiccomputing/schools/bangalore 2017.

A bank account has been opened with the State Bank of India; M. R. N. Murthy of the IISC has been co-opted as cosignatory for the bank account. Some local sponsorship has been obtained [INR 150000 (approx. GBP 1500) from TTP Labtech and INR 200000 (approx. GBP 2000) from I R Tecnology Services Pvt. Ltd]. Our intention is that the registration fee will be kept to an absolute minimum by a combination of sponsorship, low local costs and making use of speakers who will already be travelling to India for the Congress. With this in mind, we are currently working out full details of costs so that we can determine how much more sponsorship is necessary.

We have identified a number of speakers and have approached them informally so that they can keep their diaries clear for the period of the School.

\section{H. R. Powell, Chair}

\subsection{Commission on Crystallographic Nomenclature}

The members of the Commission $(\mathrm{CCN})$ are the Editors of the Union's journals and the Editors of the volumes of International Tables, the Chair of the IUCr/OUP Book Series Committee, the Chair of the Commission on Crystallographic Teaching, the Chair of the Committee for the Maintenance of the Crystallographic Information File Standard, the President of the IUCr and the General Secretary of the IUCr. The total number of members and appointed consultants exceeds 50 .

The Commission's web page invites crystallographers to bring nomenclature problems to the attention of any Commission member. Three such problems were under consideration in 2015:

(1) Nomenclature for the Field of Crystal Engineering. In 2014 ICSU funded a project titled CONcepts and termINology in Crystal Engineering (CONvINCE). The Lead Applicant for the project was IUPAC; the IUCr was listed as the Supporting Applicant. Also shown as participants were the US National Academy of Sciences and its US National Committee to IUPAC. Gautam Desiraju (then IUCr President) was named as the IUCr contact. Eventually the Chair of the CCN became involved.

A meeting connected with the project was held in Como, Italy, in August 2015. The CCN Chair attended the conference and participated in the discussions but no written proposal or draft has yet reached her or the CCN. A proposal for a Microsymposium on this subject to be held at the 2017 Congress in Hyderabad is under consideration.

(2) Nomenclature for Reticular Chemistry. During 2014 Massimo Nespolo was informed by Michael O'Keeffe that IUPAC was going to take a step towards the official recognition of the terms and symbols used for graph-theoretic description of bonding in crystal structures. In 2015 Nespolo suggested to the CCN that the IUCr become involved in the project; he was then asked to set up a Working Group. A list of members was proposed and approved; the list included one IUPAC representative already involved in the project. So far, however, all attempts to elicit responses from that Working Group have been unsuccessful.

(3) Nomenclature for Arithmetic Crystal Classes. Howard Flack has proposed that the nomenclature of arithmetic classes (of space groups) be modified. The proposed symbol of an arithmetic class consists of the symbol for the Bravaislattice type concatenated with the symbol for the crystal class (oriented point group). Thus for space group No. 45, Iba2, the symbol of the arithmetic class would be $\operatorname{oImm} 2$. The currently approved symbol is $m m 2 I$. This proposal will be discussed 
during 2016 with the aim of reaching a conclusion before the 2017 Congress in Hyderabad.

Online Dictionary of Crystallography. The CCN is responsible for maintaining this dictionary, which was established in 2006 and published in paperback form in 2014. While many crystallographers believe the dictionary to be important, the number of contributed definitions has not met expectations and the number of active contributors has remained small. Furthermore, questions have been raised about how authoritative the included definitions should be considered to be. Ways of increasing activity are being considered. It has been suggested that the various Commissions be asked to take responsibility for terms specific to their areas of interest.

The very recent addition of some 20 XAFS-related terms from the Commission on XAFS suggests the potential benefit of direct input from the Commissions, either directly as a dictionary-building exercise, or indirectly through the creation of formal metadata catalogues or CIF dictionaries to support the work of the Diffraction Data Deposition Working Group, COMCIFS etc.

\section{P. Brock, Chair}

\subsection{Commission on Crystallographic Teaching}

Since filing its last annual report in April 2015, the Commission on Crystallographic Teaching (CCT) has continued its efforts to reach out to the crystallographic community, the scientific community and the community at large by using social media. The CCT Facebook page (http:// www.facebook.com/IuCrCommissionOnCrystallographic Teaching) has 970 'likes' (a 90\% increase since our last report), and our Twitter feed (@IUCrTeach) has 98 followers (a 26\% increase since our last report). The CCT has not been as active as it had planned to be on both social-media outlets owing to extensive professional and personal commitments of its members. We do try when possible to disseminate exciting findings and important information, post career opportunities in crystallography and allied fields, and stimulate discussion. We still plan to share responsibilities on social-media sites, and also to make a concerted effort in the next year or so to review content on our web pages on the IUCr site. We will examine resources for utility and audience, reorganize content as appropriate, and update information. Our ultimate goal remains to make all our communication channels and information targeted and relevant to specific audiences, and to strengthen the brand of the IUCr.

As noted in last year's report, the CCT sponsored three Microsymposia at the Montreal Congress. A paper reporting on MS92: Crystallography Education and Training in the 21st Century: New Pedagogies, New Paradigms was published as open access in Journal of Applied Crystallography [S. Grazulis et al. (2015). J. Appl. Cryst. 48, 1964-1975]. The authors and the CCT felt that the article would have the largest and most appropriate audience in $J A C$ rather than in $I U C r J$.

Manfred Weiss, member of the CCT, is representing this Commission on the International Programme Committee for the Hyderabad Congress. The CCT will be sponsoring or cosponsoring four Microsymposia.

In the past year, the CCT has reviewed and written many supporting letters for several proposals of variable quality and made recommendations for workshops and summer schools focused on areas relevant to the discipline. As noted last year, since the Montreal Congress, the CCT now reviews and writes recommendation letters for all workshop and summer school proposals. While we have been very pleased by this development implemented by the Executive Committee, the process has been a bit cumbersome. The proposals received by the CCT continue to vary considerably in quality, and proposers continue to expect an immediate response and automatic endorsement at full funding levels. The CCT plans to work with the IUCr to create a shared file system, whereby submitted proposals in electronic form are easily accessed and reviewed. Alternatively, the CCT proposes to work with the IUCr to receive applications by means of a web-based submission system. It would be ensured that all information was there, and that the CCT had enough time (two weeks) to review a submitted application and rate/rank it. The CCT this past year has attempted to develop and implement more formalized rubrics for evaluating proposals, which will enable proposers to make the best possible case in their request, and also enable the CCT more easily to determine whether the proposals meet the mission and goals of the IUCr, to provide more useful feedback to the Executive Committee. The CCT also hopes that by streamlining the electronic process, the IUCr can avoid last-minute e-mail attachments from proposers, which may be incomplete or may not have been copied to the appropriate member of the Committee. Moreover, we hope to avoid situations that have arisen in the past year, where proposals e-mailed to the CCT for review have been lost, blocked or buried in busy e-mail inboxes.

\section{K. A. Kantardjieff, Chair}

4.10. Commission on Crystallography in Art and Cultural Heritage

The Commission continues to pursue the mission of spreading the crystallographic knowledge related to artwork and ancient materials. During the first half of 2015 some of the IYCr2014 actions were continued through the effort of the Commission members.

The exhibition In the Unusual World of Crystals, organized by Alicja Rafalska-Lasocha, was shown in Warsaw, Poland, at the Institute of Physical Chemistry PAS (January), at the Institute of Physics PAS (February), and at the University of Technology (March-July).

The following conferences, sessions and lectures were held:

(1) Organization of Microsymposium on Cultural and Historical Aspects of Crystallography at ECM-29, Rovinij, Croatia; Chair: Petr Bezdicka (http://ecm29.ecanews.org/ programme/microsymposia/\#ms50). 
(2) Symmetry, Light, Materials: the Crystallography of Cultural Heritage - invited lecture by Gilberto Artioli at the above Microsymposium.

(3) Tilings and Tessellations at Isfahan University of Technology, Isfahan, Iran - invited lecturers Jean Marc Castera, Emil Makovicky (http://isfahan.sciencesconf.org/).

(4) The Commission (CrysAC) introduced and started to organize the CrysAC workshops: one-day thematic workshops that are planned to be organized each year in different places. The first Crys AC workshop Cultural Heritage Authentication and Forensic Science will be organized in Krakow, Poland, on 18 May 2016 (Alicja Rafalska-Lasocha, Gilberto Artioli, Petr Bezdicka).

(5) Organization of the 6th Meeting on X-ray and Other Techniques in Investigations of the Objects of Cultural Heritage, which will be held in Krakow, Poland, 19-21 May 2016 (A. Rafalska-Lasocha, G. Artioli and P. Bezdicka lecturers) (http://www.biurokarier.chemia.uj.edu.pl/conf/x-ray16).

(6) Lectures on Crystallography and the International Year of Crystallography were delivered in Warsaw and Paris (Alicja Rafalska-Lasocha).

The following publications are in preparation or have appeared:

Powder Diffraction in Art and Archaeology will be a contribution by Gilberto Artioli to International Tables for Crystallography, Volume $\mathrm{H}$.

Persian Variations by Jean-Marc Castera will be published by Springer in Nexus Network Journal Architecture and Mathematics in January 2016.

Science of Crystal Structures: Highlights in Crystallography, edited by Istvan Hargittai and Balazs Hargittai, was published by Springer in 2015 .

Culture of Chemistry, edited by Istvan Hargittai and Balazs Hargittai, was published by Springer in 2015.

The Use of XRPD for the Investigation of Historic Pigments and Painting Materials in Works by Henryk Siemiradzki [A. Rafalska-Lasocha (2015). J. Anal. At. Spectrom. 30(3), 751758].

Continuing project. Celerino Abad-Zapatero continued his collaboration with Mr Painton Cowen to incorporate scientific content into the 'rose window' site (http://therosewindow.com/ TheRoseWindow2/Rose-numbers.htm).

Gilberto Artioli and Alicja Raflaska-Lasocha were invited to be members of the International Programme Committee for the Hyderabad Congress.

\section{G. Artioli, Chair and A. Rafalska-Lasocha, Secretary}

\subsection{1. ad interim Commission on Crystallography of Materials}

Summary. Our ad interim Commission was approved at the meeting of the Executive Committee of the IUCr in Boston (July 2012). This is the newest and in many ways a unique Commission. It covers a high-impact and deeply crystallographic topic that has not been covered by other IUCr Commissions.
Members of the Commission took part in the following activities:

Participation in the International Programme Committee for the Hyderabad Congress: the Commission was represented by Evgeny Antipov and Shilun Qiu.

Organization of the International Symposium on Materials at Extreme Conditions (Inter MEX) 2015, 6-8 November 2015, Beijing, People's Republic of China, organized by Changqing Jin (Institute of Physics, Beijing, People's Republic of China) and Rajeev Ahuja (University of Uppsala, Sweden), with more than 110 participants, 30 oral presentations and 30 posters.

Organization of workshops to disseminate knowledge and technical skills:

8th USPEX Workshop on Crystal Structure Prediction, 2024 January 2015, Shiv Nadar University, India, organized by Priya Johari (Shiv Nadar University, India), Artem R. Oganov (Stony Brook University, USA) and Sayed Faheem Naqvi (Anand International College of Engineering, Jaipur, India), with 90 participants.

9th USPEX Workshop on Crystal Structure Prediction, 2530 June 2015, Poitiers University, France, organized by Gilles Frapper (Poitiers University, France) and Artem R. Oganov (Stony Brook University, USA), with 35 participants.

10th USPEX Workshop on Crystal Structure Prediction, 20-23 August 2015, Beijing Computational Science Research Center, People's Republic of China, organized by Artem R. Oganov (Stony Brook University, USA), Yan-Ling Li (Jiangsu Normal University, People's Republic of China) and QingFeng Zeng (Northwestern Polytechnical University, People's Republic of China), with 110 participants.

\section{A. R. Oganov, Chair}

\subsection{Commission on Electron Crystallography}

The year 2015 demonstrated active continuation in development of methods of structural electron microscopy. Impressive results were published by D. S. Subramaniam, where he and his colleagues achieved 3.3 and later $2.7 \AA$ resolution using methods of cryo electron microscopy using high-level microscopes (FEGs, $300 \mathrm{KeV}$ ) and direct detectors. That was followed by a number of other publications from China, UK, USA, and France demonstrating structures at a resolution of 3-4.5 $\AA$.

The Commission was fully committed to use all opportunities to take a leadership role in training the young generation of scientists in electron crystallography and diffraction, including imaging. Various workshops, summer schools and symposiums on electron crystallography and microscopy were organized around the world, and the Commission was directly involved in the following events.

In Europe: ECS 2. Second European Crystallography School, Spain, 31 August - 5 September 2015. The programme covered new requirements for education and training for modern crystallography. It was divided into four modules: (1) basics of crystallography; (2) symmetry, crystal/structure 
association and diffraction methods; (3) crystallography in biology and materials sciences; (4) electron crystallography. The school was organized by D. García-Granda, University of Oviedo, Spain. Sponsorship was provided by the IUCr, PCTIasturias, NannoMegas and other companies.

XLIV Annual Meeting of the AIC, Italy, 14-18 September 2015. Plenary Lectures were by Lukas Palatinus (Institute of Physics of the ASCR, Prague, Czech Republic), Bartolomeo Civalleri (Università di Torino, Italy), and Jan Pieter Abrahams (Universiteit Leiden, The Netherlands).

Cristallographie Electronique, France, 16-20 November 2015. The organizers were D. Jacob (Université de Lille, France), P. Roussel (Ecole Nationale Supérieure de Chimie de Lille, France), and P. Boullay (CNRS, CRISMAT, France). The first electron crystallography school organized by the SFMU in collaboration with the Association Française de Cristallographie (AFC) was held at UMET Laboratory at the Université de Lille 1, 16-20 November 2015. The school aimed to train students to determine structures and microstructures at the nanoscale by electron diffraction in a transmission electron microscope (TEM). In particular it covered recent developments associated with the use of new techniques of acquisition and/or analysis of data such as precession, tomography and orientation mapping.

Electron Crystallography School, Porec, Croatia, 28-31 August 2015. This school was related to another crystallographic event - ECM29, as a satellite meeting. The neighbourhood of the crystallographic community gave a unique possibility to expose electron crystallography to a broad audience of young scientists. Thirty students participated in the school, coming from Poland, Germany, UK, Sweden, Spain, Turkey, Ireland, Czech Republic, Italy, Argentina, Croatia, Belgium and Switzerland. A three-day programme included lectures, a poster session and practicals. Morning sessions had four lectures covering the following topics: basic crystallography concepts and their application to electron diffraction, methods of electron-diffraction tomography, crystallographic structure-analysis methods in electron diffraction, and highlighting topics related to the lattice defects, modulated structures and poorly crystalline materials, observed using electron scattering. Practicals were organized during the afternoon sessions. The students had a chance to work with different software packages for electron diffraction data processing and to perform structure analyses of simple compounds by applying different techniques such as direct methods and charge flipping.

This school provided an opportunity for young scientists to show their results and discuss scientific and social questions both with students and lecturers.

Sponsorship was organized by T. Gorelik from the private sector, the IUCr, and the European Microscopy Society.

Electron Diffraction for Quantitative Surface Structure Determination. ICSOS Workshop-3 on Surface Structures, Lodz, Poland, 19-26 July 2015. Chair of the Organizing Committee was D. I. Zasada. The workshop covered the experimental and theoretical aspects of different techniques employed for the structure determination of surfaces, inter- faces and nanostructures. The workshop was aimed at graduate students and post-docs in physics, chemistry and materials science. Fifteen students from Poland, Germany, The Netherlands, and the Czech Republic attended. Sponsorship was provided by the IUCr and used to help students with contributions towards their subsistence and travel expenses.

In the USA: ICESS-15. International Conference on Electron Spectroscopy and Structure, USA, 28 September - 2 October 2015.

Participation in organizing the programme for the Hyderabad Congress. Professor Van Dyck has been elected to represent the Commission on the International Programme Committee (IPC) of the Hyderabad Congress. A subcommittee of the Commission (E. V. Orlova, D. Van Dyck and L. Marks) has followed proposals of members of the Commisison suggesting the list of Microsymposia. Professor D. Van Dyck was very successful in representing the scientific directions and new developments suggested as the most advanced topics to the IPC.

\section{E. Orlova, Chair}

\subsection{Commission on High Pressure}

The 14th Workshop of the Commission on High Pressure (CHP) was held 12-15 September 2015, at the Brazilian Synchrotron Light Laboratory (LNLS) in Campinas, Brazil. The Local Organizing Committee was chaired by Narcizo Souza-Neto. The workshop was held immediately after the $1 \mathrm{st}$ Latin-American Crystallographic Association (LACA) Meeting in São Paulo, and was promoted by the Latin American Crystallographic Association jointly with the 22nd Sociedade Brasileira de Cristalografia (SBC Meeting), and before the 25th RAU (LNLS Annual Users Meeting), supported by the Brazilian Synchrotron Light Laboratory.

The 14th CHP Workshop was attended by 75 participants from 14 countries. The Workshop focused on recent advances in high-pressure techniques and research at synchrotron, neutron and laboratory-based facilities. Lectures covered structural phase transitions and their kinetics, new materials synthesis, earth and planetary science, soft and biological matter, physical and chemical properties, and theory and computation. About 30 lectures were presented by scientists from different countries, and the subjects covered various aspects of high-pressure crystallography and its methodology applied over a wide scope of scientific research, including basic physics and chemistry, as well as the more applied sciences of geology, metallurgy, porous materials etc. The infrastructure for high-pressure research, particularly the synchrotron and neutron sources and their development, were discussed. During the Workshop the participants toured the LNLS in Campinas and visited the ultra-low-emittance synchrotron source SIRIUS, currently under construction. A detailed report on the Workshop was given in the IUCr Newsletter Volume 23, Issue 3.

The Workshop followed the 29th European Crystallographic Meeting in Rovinj, Croatia, where Kamil Dziubek 
represented the CHP in the session on metadata deposition. In Campinas a CHP Sub-commission was established for preparing the guidelines, rules and formats for depositing the metadata and data of high-pressure experiments. The Metadata Deposition Sub-commission has been joined by Kamil Dziubek, Ross Angel, Elena Boldyreva, Guoyin Shen, Boris Zakharov and Andrzej Katrusiak. This Sub-commission has also undertaken the task of reviewing the CIF formats used for high-pressure experiments.

It was decided in Campinas that the next 15th IUCr CHP Workshop would be held in Seoul, South Korea, 20-23 September 2016, at Yonsei University, with the Local Organizing Committee chaired by Yongjae Lee, who provided a presentation about the venue. Later, after broader consultations, the venue was changed to POSCO International Center, Pohang Accelerator Laboratory, South Korea, and the dates were extended to 20-24 September 2016. Registration for this workshop may be carried out at http://2016IUCrHPworkshop.yonsei.ac.kr.

An application for supporting young scientists to attend the 15th IUCr CHP Workshop was submitted to the IUCr.

The Commission held numerous discussions on the representation of high-pressure research in the prestigious Hyderabad Congress to be held in 2017. The candidates for lecturers and Chairs of suggested sessions were chosen collectively and submitted to the International Programme Committee.

The Commission also continues fostering small workshops and meetings promoting high-pressure crystallography. Two such workshops were organized by the CHP Chair in 2014: one in Poznan, Poland, the 8th Frolic Goats High-Pressure Workshop will take place 26-28 April 2016; another workshop held 19-24 October 2015, at the University of Witwatersrand, South Africa, organized together with Andreas Lemmerer and Len Barbour of the University of Stellenbosch, was entitled High-Pressure Magic in Wits, Johannesburg in South Africa.

Other CHP members and consultants were also involved in organizing summer schools dedicated to high-pressure crystallography and in other ways of disseminating high-pressure techniques in crystallography and material sciences. One major such event was the High-Pressure Crystallography Course being prepared by CHP member Francesca Fabbiani, acting as one of the Course co-directors. All CHP members are encouraged to contribute to small-scale local highpressure workshops.

Dissemination of high-pressure techniques to new applications in crystallographic X-ray laboratories continues to be one of the main tasks of the CHP. We aim at convincing more crystallographers to apply pressure, to have a diamond-anvil cell in every laboratory and the skills for performing all stages of high-pressure experiments on one's own equipment in the laboratory.

A round robin for high-pressure experiments is still planned, in order to determine possible systematic errors in high-pressure results.

Finally, the Chair invited distinguished high-pressure scientists to prepare historical mini-reviews on high-pressure research and high-pressure crystallography in their countries.
Presently there are many scientists who witnessed the beginning of high-pressure research in their countries and they are often in possession of valuable photographs and equipment that are most interesting and precious for the broad crystallographic community. Therefore provisional arrangements were made with the Editor of the IUCr Newsletter (Dr William Duax), who enthusiastically welcomed this idea and agreed to publish this series of historical mini-reviews. About 20 highpressure researchers from different countries have already been invited to contribute to this series.

\section{A. Katrusiak, Chair}

\subsection{Commission on Inorganic and Mineral Structures}

Members and consultants of the Commission (CIMS) discussed various issues via e-mail. Other forms of communication were provided by other occasional meetings or conferences or by using the web site. The latter is kindly maintained by M. Nespolo (http://www.crystallography.fr/ cims/).

The IUCr Commission on Structural Chemistry (CSC) and CIMS maintained their links. P. Mercier is now the liaison person representing CSC in CIMS and vice versa.

CIMS also maintains strong links with the new Commission on NMR Crystallography and Related Methods. J. Rocha is the liaison person and also a consultant for that Commission.

P. Mercier continues to act as liaison officer of CIMS with the $I U C r$ Newsletter.

Strong links exist between CIMS and the European Crystallographic Association: O. Yakubovich (CIMS member) was a member of the Executive Committee; the Secretary of Special Interest Group SIG-05 is O. Siidra, the Chair is S. Krivovichev (CIMS consultant) and F. Hatert is Vice-Chair (CIMS member) (ECA - SIG-05, http://sig5.ecanews.org/).

There are very good relationships between CIMS and the European Mineralogical Union (EMU, http://eurominunion.org/); R. Oberti (EMU Past President) is a member of CIMS and also Commissioning Editor of the EMU's Notes in Mineralogy. In 2015, Planetary Mineralogy was published as Volume 15. Volume 16, Mineralogical Crystallography, coedited by J. Majzlan, S. Krivovichev (CIMS consultant) and J. Plasil, will be published in 2016. For the same series, together with Gilberto Artioli (Chair of the Commission on Crystallography in Art and Cultural Heritage), R. Oberti has been editing the volume The Contribution of Mineralogy to Cultural Heritage, to be published at the end of 2016.

M. Nespolo is Book Review Editor for the IUCr journals.

G. Ferraris was the editor of a collection of papers presented at the meeting Impact of Crystallography on Modern Science (Quaderni dell' Accademia delle Scienze di Torino, 21, 2015), held at the Accademia delle Scienze di Torino on 25 June 2014, to celebrate the International Year of Crystallography.

R. Oberti is Chair of the Italian National Committee for Crystallography. 
P. Mercier has been Chair of the Canadian National Committee for Crystallography since August 2015.

CIMS was involved in the following meetings held in 2015:

R. Oberti was a member of the Scientific Committee of the 8th European Conference on Mineralogy and Spectroscopy, held in Rome, Italy, 9-11 September 2015, at the headquarters of CNR, the National Research Council (http://www. ecms2015.eu). 120 attendees discussed the Plenary talks of Frank C. Hawthorne (University of Manitoba), Laurence Galoisy (Université Pierre et Marie Curie, Paris), Robert D. Shannon (University of Colorado), Giancarlo Della Ventura (University Roma Tre), Bjorn Winkler (University of Frankfurt) and Catherine McCammon (University of Bayreuth). The scientific programme focused on the interplay between short-range and long-range information to account for the stability and physical properties of crystalline and amorphous materials.

O. Yakubovich was member of the Programme Committee of the 29th European Crystallographic Meeting, held in Rovinj, Croatia, August 2015. J. Rocha and O. Yakubovich gave invited talks at this event.

C. Ling was Chair of the Organizing Committee of the 2nd Asia-Oceania conference on Neutron Scattering (AOCNS2015), held in Sydney, Australia, 19-23 July 2015 (http://aocns2015.com).

CIMS has been involved in the organization of the following meetings:

S. Krivovichev and R. Oberti are members of the Scientific Committee of the 2nd European Mineralogical Conference to be held in Rimini, Italy, 11-15 September 2016 (http:// emc2016.socminpet.it/). Forty-two sessions will discuss interactions between mineralogy, petrology and geochemistry. The focus will be on the impact of crystallography on the mineralogy and petrology of the Earth and extraterrestrial bodies. One of the six Plenary lectures, delivered by Karen Appel (European XFEL Hamburg) is dedicated to the exciting perspectives for Earth Sciences provided by XFEL techniques.

G. Ferraris chairs the Scientific Committee of the meeting Mineral Phases and Synthetic Analogues in Earth and Materials Science, to be held at the Accademia dei Lincei, Rome, Italy, 13-14 June 2016; J. Rocha is an invited speaker.

J. Rocha is a member of the Organizing Committee of conference SMARTER5, to be held in Bayreuth University, Germany, 4-8 September 2016 (http://www.smarter5.unibayreuth.de/de/). This event is now promoted by both CIMS and the Commission on NMR Crystallography and Related Methods.

P. Mercier is a member of the Programme Committee for the 2017 IUCr Crystallographic Computing School to be held in Bangalore, India, 15-20 August 2017.

CIMS supported the application for funding by the IUCr of the following meetings to be held in 2016:

11th USPEX Workshop on Evolutionary and Interpretation Methods for Discovering the Structures and Rationalizing the Properties of Crystalline, Surface and Nanoparticles Materials, Varenna, Lake Como, Italy, 5-9 June 2016.
Workshop on Crystallography for Space Sciences, to be held at Instituto Nacional de Astrofisica Optica y Electronica, in Puebla, Mexico, 17-30 April 2016.

\section{J. Rocha, Chair}

\subsection{Commission on Magnetic Structures}

During the first half of 2015, the IUCr magCIF working group generated numerous additions/revisions to the new magCIF dictionary project. The revisions included (1) the addition of support for incommensurate structures, which had been negotiated during the previous year, (2) many revisions in response to feedback from working-group members regarding OG and BNS settings of commensurate magnetic space groups, (3) changes to the structure of tags that describe transformations to other settings, and (4) many other minor improvements. A new tag structure was also tentatively introduced, which allows the description of magnetic propagation vectors in OG settings.

Ten Commission members and consultants conducted an internet-video meeting on 24 November 2015. Participants included Andrew Wills, Alexander Pirogov, Vladimir Pomjakushin, Vaclav Petricek, Danny Litvin, Wieslawa Sikora, Taku Sato, Juan Manuel Perez-Mato, Juan Rodriguez-Carvajal and Branton Campbell. The meeting focus was the recommendation of Keynote speakers and Microsymposia topics for the Hyderabad Congress in 2017. A prioritized list of topics and speakers was agreed upon in the weeks following the meeting, many of which are likely to be of interest to other Commissions. Commission member Taku Sato had been elected earlier in the year to serve on the International Programme Committee of the Congress and will attend the IPC planning meeting in Hyderabad in March 2016. Following Commission discussions at the Montreal Congress in 2014, Juan presented plans for a one-week school for 30 participants in late 2016, where topics could include magnetic structures and their descriptions, magnetic symmetry, the determination of magnetic structures etc.

The Commission's web site at http://magcryst.org continues to promote meetings that give attention to high-quality magnetic-structure research. At many of these events, our Commission members gave featured presentations, developed workshop components, organized or hosted workshops and Microsymposia, and presented lecture courses. Highlights include the following:

Aperiodic 2015, Prague, Czech Republic, 30 August - 4 September 2015 (Vaclav Petricek, meeting organizer).

5th School on Representational Analysis and Magnetic Structures (RAMS), University of Maryland, College Park, USA, 2-7 Aug 2015 (Juan Manuel Perez-Mato, lecturer).

European Conference on Neutron Scattering, Zaragoza, Spain, 30 August - 4 September 2015 (meeting co-sponsored by the Commission; Vladimir Pomjakusin, session organizer; Juan Manuel Perez-Mato, Plenary lecture; over 60 sessions with content involving magnetic structures and phenomena). 
European Crystallographic Meeting, Rovinj, Croatia, 23-28 August 2015 (Wielslawa Sikora, session organizer; Juan Manuel Perez-Mato, invited presentation).

Second Balkan School on Fundamental Crystallography and Workshop on Magnetic Symmetry, Istanbul, Turkey, 13-19 July 2015 (Juan Manuel Perez-Mato, lecturer).

British Crystallographic Association Meeting, York, UK, 30 March - 2 April 2015 (Branton Campbell, workshop lecturer).

Fullprof School, ILL, Grenoble, France, 2-5 March 2015 (Juan Rodriguez-Carvajal, organizer).

\section{B. Campbell, Chair}

4.16. Commission on Mathematical and Theoretical Crystallography

In 2015 the members and consultants of the Commission (MaThCryst) collaborated actively but mainly via e-mail and/ or internet. Other forms of communication were in person at occasional events, meetings, conferences or schools. Most of the discussions were devoted to the planned activities of the Commission for 2016, including (i) the International School on Fundamental Crystallography with Applications to Electron Crystallography that will be held in Antwerp, Belgium (June 2016), organized together with the Commission on Electron Crystallgoraphy (MaThCryst coordinator J. Hadermann); (ii) the organization of mini-symposium sessions at the SIAM (The Society for Industrial and Applied Mathematics) conference on Mathematical Aspects of Material Science, Philadelphia, USA, May, 2016 (MaThCryst coordinator G. McColm). Unfortunately, due mostly to organization problems, the preparation of some of our activities scheduled for 2016 was delayed and initial plans had to be modified. One of them concerns the International School on Fundamental Crystallography (ISFC), the Fifth MaThCryst School in Latin America, which initially was planned to take place in Bogota, Colombia, May-June 2016. The lack of response of the local organizers obliged us to change the location and the time schedule of the school: thanks to the great efforts and efficiency of Commission coordinators E. E. Rams and L. Suescun, the school will take place in Havana, Cuba, OctoberNovember 2016. The Second Philippine Workshop on Mathematical Crystallography, planned initially for 2016, had also to be re-scheduled, and hopefully, will take place in May 2017; Ma L. de la Peñas will act as the main local organizer and MaThCryst coordinator.

All the activities of the Commission are chronicled regularly on MaThCryst's web page thanks to M. Nespolo, and can be found at http://www.crystallography.fr/mathcryst/ index.php. G. McColm is maintaining a blog on mathematical crystallography, called Crystal Mathematician, at http://blogs. iucr.net/crystalmath, and this is devoted to mathematics of crystal design and analysis.

In 2015 the Commission continued actively to promote mathematical and theoretical crystallography by organizing, supporting and promoting meetings, workshops and educational events worldwide. The main educational and scientific activities can be summarized as follows:

$(A)$ International schools and workshops:

(1) The Second Balkan School on Fundamental Crystallography and Workshop on Magnetic Symmetry and Its Application in Magnetic Structure Descriptions, 13-19 July 2015, Institute of Theoretical and Applied Physics, Istanbul, Turkey (MaThCryst coordinator M. I. Aroyo), was organized as a follow-up to the International School on Fundamental Crystallography held in Gjulechitza, Bulgaria, in 2013.

There were a total of 32 applicants coming from Turkey, Bulgaria, People's Republic of China, Spain, Romania, Switzerland, Russia and Japan. The international lecture team included lecturers from: Spain (M. I. Aroyo and J. M. PerezMato, University of the Basque Country); Bulgaria (R. Nicolova and B. Chivatchev, Bulgarian Academy of Sciences); and Turkey (E. Tasci, University of Hacettepe). As for the local organizers, academics and graduate students from various Universities in Turkey (Istanbul Technical University, Middle East Technical University and Bilkent University) took part. This event was also a collaboration of two of the largest Universities of Turkey as Hacettepe University (Ankara) was the main contributor in the organization while Istanbul Technical University (Istanbul) gave support for the venue and hosting together with the Institute of Theoretical and Applied Physics. National and international crystallography organizations (IUCr, ECA, Turkish National Crystallography Association) also provided support and promoted the event. Most of the students (21 from 32 participants) benefited from partial to full grants.

The programme of the school included basic and advanced topics from fundamental crystallographic group theory to applications in phase transitions and structural relationships. The school had an integrated Workshop on Magnetic Symmetry, in which the students had direct experience with the usage of recently tabulated magnetic symmetry groups in digital databases. For the application of the theory studied, the Bilbao Crystallographic Server's programs were used. Each lecture was accompanied by a series of guided exercises. Most of the participants gave short oral presentations followed by a discussion of their research projects. Details on the programme of the school, didactic material, photographs etc. are available at the web site http://www.crystallography.fr/ mathcryst/istanbul2015.php.

(2) On the occasion of the International Year of Crystallography, the initiative of proposing a training course in symmetry and group theory in Japan was launched in August 2014 by the Photon Factory, co-sponsored by the Crystallographic Society of Japan, with lecturer M. Nespolo, Université de Lorraine (founder and former Chair of MaThCryst). The unexpected popularity of this course (the maximal number of participants was reached only a few hours after opening the registration) has prompted the organizers and sponsors to repeat it and eventually transform it to a regular event, running twice a year, with the Crystallographic Society of Japan as one of the main organizers. 
In 2015 the training course was held twice, in March in Tsukuba, and in August in Osaka. Both events were again sold out in a few hours. Despite a very intensive programme (lectures from 9 am to $7 \mathrm{pm}$, with additional question-andanswer sessions after dinner), participants enthusiastically took part in all the lectures and practical exercises. At the end of the course, they received a certificate of attendance. Photographs are available at the IUCr gallery web site.

Several factors account for the unexpected success of these training courses:

(a) the participants, who come from very diverse backgrounds, including several from industry, meet strong difficulties in obtaining the crystallographic knowledge they need in their daily work;

(b) the language barrier represents a significant obstacle for many participants, who would not attend such an event, should it be offered in a language different from their mother tongue;

(c) participation is free of charge, the venues offer the possibility of cheap accommodation, and financial support is offered to students and post-doctoral fellows, thanks to the generous support by the main organizers and sponsors.

Negotiations are currently held to offer these training courses also as part of the curriculum of the Graduate University for Advanced Studies. Further details on the training courses can be found at http://www.crystallography.fr/ mathcryst/Tsukuba2015.php and http://www.crystallography. fr/mathcryst/Osaka2015.php.

(3) The international scientific school Combined Topological and DFT Methods for Prediction of New Materials was held 15-20 September 2015 at Samara State University, Russia. Samara Center for Theoretical Materials Science (SCTMS), Samara State University and the International Union of Crystallography organized the school (MathCryst coordinators D. Proserpio and V. Blatov).

The School gathered together 20 post-graduate students and young researchers from Russia (V. S. Sobolev Institute of Geology and Mineralogy RAS; Nikolaev Institute of Inorganic Chemistry RAS; Lomonosov Moscow State University; South Ural State University), Germany (Friedrich Schiller University, Jena; TU Bergakademie Freiberg), Italy (University of Padova), UK (Cardiff University), India (University of Delhi; Indian Institute of Science Education and Research), South Korea (Gyeongsang National University) and Vietnam (Vietnam National University). The programme of the school was highly topical and included lectures, practical training and individual consultations. Among the lecturers during the school was the leading scientist of SCTMS D. M. Proserpio (University of Milan, Italy), the director of SCTMS V. Blatov, the head of SCMTMS Laboratory of Mathematical Modeling of Materials V. Saleev as well as young scientists from SCTMS A. Shipilova and A. Kabanov. They worked closely with the participants, answered their questions and provided expertise on various topics of materials science and research methods. Material from the meeting can be found at http://english. sctms.ru/novosti_centra/nc_20151005_01/.

(4) On 21-23 May 2015, Samara Center for Theoretical Materials Science held the IUPAC project meeting and workshop Topology Representations in Coordination Networks, Metal-Organic Frameworks and Other Crystalline Materials (MaThCryst coordinators D. Proserpio and V. Blatov). Co-organizers of the meeting were the International Union of Pure and Applied Chemistry (IUPAC), International Union of Crystallography, Samara State University and Chalmers University of Technology (Sweden). Task-group members of IUPAC from all over the world (Sweden, Italy, Russia, USA, Brazil, Australia, Republic of Korea, Republic of South Africa) took part in the meeting. Apart from the main organizers of the event, D. Proserpio and V. Blatov, MaThCryst was represented by S. Hyde and J.-G. Eon.

During the first day of the project meeting, the scientists delivered their reports and discussed current issues of theoretical materials science and crystal chemistry. The poster session, where post-graduate students and young researchers from Samara Center for Theoretical Materials Science presented the results of their research work, concluded the first day. Scientific abstracts of the meeting are available. During the poster session, the young participants had excellent opportunities to discuss their research with top scientists and receive valuable references and recommendations. During the remaining two days IUPAC members held a workshop, during which they worked out recommendations on applicability of new scientific terms in chemistry. On 22 May 2015, IUPAC members took part in a press conference and answered the questions of Samara journalists.

(B) Publishing activities:

(1) A Special Issue of Zeitschrift für Kristallographie (published in December 2015 with Guest Editors M. Nespolo and M. I. Aroyo) was devoted to the recent developments and the current state of art in the field of mathematical and theoretical crystallography. The issue includes articles of members and consultants of the Commission: G. McColm's contribution focuses on the generation of periodic graphs for crystal design, M. Tanemura and T. Matsumoto disclose the fascinating world of ellipses and their closest packing while in the contribution by M. Loquias and P. Zeiner the idea of colour symmetry, originally defined for symmetry of lattices, is extended to the analysis of coincidence site lattices. The Special Issue was dedicated to the memory of $\mathrm{H}$. Wondratschek.

(2) Members and consultants of the Commission have contributed actively to different IUCr publishing activities:

(i) 6th edition of International Tables for Crystallography Volume A, Space-Group Symmetry, Editor M. I. Aroyo; B. Souvignier (chapters on general introduction to group theory, on space-group symmetry, on space groups and their descriptions), K. Momma (generation of the general-position diagrams for cubic space groups, section on computer preparation of Volume A), E. Koch (chapters on lattice complexes of space groups and space-group normalizers), D. Litvin (chapters on special topics of space groups, and magnetic subperiodic groups and magnetic space groups).

(ii) Editors of IUCr journals: M. Nespolo (Book-Review Editor for all IUCr journals); J.-G- Eon (Co-editor of Acta A), D. Pandey (Co-editor of $J A C$ ). 
(C) Further activities. During 2015, members of the Commission have also been involved in a number of other activities related to MaThCryst purposes:

(1) Participation in crystallographic meetings and conferences: (i) L. Suescun attended the IYCr Legacy Meeting, Rabat, Morocco (April 2015), where he presented IYCr activities in Latin America and Uruguay. MaThCryst activities ISFC2014 and ISFC2010 were mentioned in each presentation, respectively; (ii) L. Suescun participated in the I Congreso Peruano de Cristalografia, Lima, Peru (http://fisica.unmsm.edu.pe/index.php/I_Congreso_Peruano_ de_Cristalografia, August 2015); contacts were made for the possible organization of ISFC2018 at Universidad Nacional Mayor de San Marcos, Lima, Peru; (iii) E. Estevez and L. Suescun attended the Latin-American Cystallographic Association Meeting and 22nd Brazilian Crystallographic Association Meeting, Sao Paulo, Brazil (September 2015). The possibility to re-schedule ISFC2016 for Havana, Cuba, in November 2016 was discussed and decided; (iv) Ma L. De Las Peñas attended the Aperiodic Conference in Prague, Czech Republic, 30 August - 4 September 2015.

(2) Tutorship and lectureships: (i) L. Suescun: tutor and lecturer at the VII Argentinian Crystallographic Association School, La Plata, Argentina (October 2015); (ii) E. Estevez: lecturer at the State University of Campinas, Brazil, on crystallography and the mathematics of disordered materials; (iii) M. I. Aroyo: lecturer and co-Chair of the Scientific and Organizing Committees of the 2nd European Crystallographic School (Mieres, Spain, August-September 2015).

\section{I. Aroyo, Chair}

\subsection{Commission on Neutron Scattering}

The Commission (CNS) promotes the use of neutron scattering by encouraging the publication of information on the capabilities of neutron sources and instrumentation and by supporting symposia, schools and workshops that educate researchers about the unique information that can be provided by neutron scattering. Several members of the Commission are actively involved in developing neutron sources and new neutron-scattering technologies and methods.

The construction of the European Spallation Neutron Source in Sweden, which is projected to produce the first neutrons in 2019, and the Chinese Spallation Neutron Source (CSNS), which is expected to be operational in 2018, are in progress. The operation of the Spallation Neutron Source (SNS) in the USA is ongoing. The beam power for J-PARC/ MLF is temporarily down owing to target trouble, but will recover next summer. Further, several new neutron-scattering instruments were brought into user programmes at neutronscattering facilities across the world.

Commission members were also involved in organizing several meetings that took place in 2015, including various annual meetings of regional crystallographic associations. A notable neutron conference in 2015 was the 2nd Asia-Oceania Conference on Neutron Scattering (AOCNS 2015), which was held in Sydney, Australia. This conference was hosted by the Asia-Oceania Neutron Scattering Association (AONSA) and sponsored by ANSTO. The programme covered a wide range of topics, with six themes included, satellite meetings, regional society meetings, industrial exhibits, and a tour of ANSTO's OPAL reactor. The 6th European Conference on Neutron Scattering was held in Zaragoza, Spain. The conference attracted more than 650 participants from 31 different countries and the main topics in the conferences covered eight fields including Cultural Heritage and Archaeometry.

A Gordon Research Conference (GRC) on Neutron Scattering, which is a new series featuring several worldleading neutron-scattering scientists, also took place in Hong Kong.

Several neutron schools were supported by Commission members: the 7th AONSA Neutron School at J-PARC in Japan; the 14th Oxford School on Neutron Scattering in the UK; the 14th PSI Summer School on Condensed Matter Research at PSI in Switzerland; and the 2015 Inelastic Neutron Scattering School 2015 (INSS2015) at ANSTO, Australia.

The 7th AONSA Neutron School at J-PARC, which was canceled twice owing to the disaster of the Great East Japan Earthquake in 2011 and in 2013 owing to the accident at the Hadron Experimental Hall in J-PARC, was successfully held with 41 participants.

Commission members were involved in planning activities for several important neutron conferences in 2016.

\section{P. Langan, Chair}

\subsection{Commission on NMR and Related Methods}

The Commission was established in mid-2014, so this report is on its first full year of operation. Since the Commission involves ESR/EPR as well as NMR, we now have Sabine Van Doorslaer (Belgium) as a consultant. We have also added a second consultant, namely Tsunehisa Kimura (Japan), to widen our geographical representation.

As ever, details of the objectives and activities of the Commission can be found on the IUCr web site at http:// www.iucr.org/iucr/commissions/nmr-crystallography. In its first year, the Commission has been finding its feet and trying to make its existence known to the general crystallographic and NMR/ESR communities. We have had ongoing discussions with Acta Crystallographica about the appropriate way to encourage the submission of research papers involving NMR/ ESR. The journal has, of course, been reconsidering the contents of its various journals. NMR is now mentioned specifically in the remit of Acta Crystallographica Section D (Structural Biology) and is implicitly included for the other IUCr journals (except Journal of Synchrotron Radiation). Articles for a Special ssue of Acta Crystallographica Section C have been submitted, with publication in December 2016. We 
anticipate that several of the journals will appoint a magnetic resonance expert to their editorial boards and the Commission has submitted names of suitable people to the Commission on Journals.

The Commission is encouraging the planning of conferences that address NMR crystallography as a topic. In consequence, the British Radiofrequency Spectroscopy Group devoted its traditional one-day Christmas-time meeting in London on 14 December 2015 to the topic NMR and Crystallography, as discussed with the British Crystallographic Association (see https://www.iopconferences.org/iop/frontend/reg/tOtherPage. csp?pageID=403663ANDef_sel_menu=5572ANDeventID= 815ANDeventID=815). The ideas and intentions of the Commission have been presented in talks at several conferences, including some in Poland and the USA. An article on NMR crystallography has been published in Chemical and Engineering News.

The proposal to establish the Commission was formally presented by Professor Francis Taulelle (with support from Rod Wasylishen and Manish Mehta) to the Executive Committee of the IUCr on 1 August 2014, at its meeting in Montreal prior to the triennial Congress. Following a brief discussion, the Executive Committee gave a warm formal approval to the existence of the Commission with an amended title: Commission on NMR Crystallography and Related Methods, to emphasize the inclusion of such techniques as EPS/ESR.

Details of the objectives and activities of the Commission can be found on the IUCr web site at http://www.iucr.org/iucr/ commissions/nmr-crystallography. The Commission's web site will be developed further and new members of the Commission are currently being appointed (especially to broaden the geographic representation and to add expertise in ESR spectroscopy).

A series of SMARTER conferences has been instituted on the topic of NMR crystallography, with participants from both the NMR and the diffraction communities. The fourth of this type was held in Durham (UK) in September 2014; these meetings are now sponsored (inter alia) by the IUCr. The next SMARTER meeting will be in Bayreuth, Germany, in 2016 (organizer J. Senker).

Discussions are underway to determine how research papers involving NMR crystallography will be incorporated into Acta Crystallographica. Initially, it has been decided to publish a Special Issue of Acta C: Structural Chemistry, with a publication in 2016.

Establishment of this new Commission is not before time! Although new to the IUCr, NMR has been known as a method of obtaining detailed molecular-level information on crystalline materials for about 60 years. For instance, in 1948 (only three years after the discovery of the NMR phenomenon) Pake reported the measurement of the internuclear distance between protons in water molecules involved in gypsum. A year later, Gutowsky et al. commented that 'the development of experimental methods for observing nuclear magnetism has provided a means of investigating certain aspects of molecular and crystal structure'. However, much higher resolution was attainable for solutions than for solids, so for several decades, the former dominated NMR work and the latter languished. This situation changed with the development of cross polarization, magic-angle spinning and high-power proton decoupling in the mid-1970s. This combination of techniques resulted in much higher resolution for solids, so that applications to crystalline materials have become common. The crystallography community in general has been slow to adopt NMR as one of its key techniques, so NMR and diffraction methods have largely involved separate communities until recently. However, it has become obvious that the complementarity of these methods requires a closer interaction of their practitioners, so the formation of a new IUCr Commission at this point makes sense. The development of computational methods for refining structures from NMR data has added urgency to this matter.

The requirement for closer integration of NMR with other methods of studying crystalline materials was highlighted by a short article in the IUCr Newsletter in 2005, following an International School on Crystallography at Erice the previous year, which had included lectures on NMR. It should be noted that the Commission will also deal with other magnetic resonance techniques, such as ESR/EPR, NQR and muon spin resonance. A link has been established with developments in connecting chemical shifts with crystal structure via computation, carried out by the Collaborative Computational Project for NMR Crystallography (funded by EPSRC in the UK). The Commission has been invited to plan a one-day meeting on NMR crystallography in London in December 2015 for the British Radiofrequency Spectroscopy group.

It is worth summarizing here just a few of the salient points about NMR crystallography for the benefit of newcomers to the subject:

NMR is generally used to study microcrystalline samples and does not require single crystals.

It gives information about short-range environments of atoms in a complementary fashion to diffraction techniques, which rely on long-range order.

Motion in solids can be monitored and investigated.

Crystallographic disorder can be detected and evaluated.

Amorphous systems yield detailed information about molecular-level structure.

The structure of heterogeneous materials can also be evaluated by NMR.

Since the technique is based on nuclei not electron density, the correct positions of hydrogens are relevant.

It can be used in combination with powder diffraction (and even, in some circumstances, on its own) to obtain full structural information.

The sheer versatility of NMR should also be emphasized. This arises from $(a)$ the fact that nearly all the elements of the Periodic Table have a suitable isotope for study (and the frequency ranges for their signals do not in general overlap) and $(b)$ there is a wide variety of experiments that can be performed by varying the radiofrequency pulse sequences used. Further details can be seen in a number of books and themed issues of several journals. There is, for example, a 
recent (2009) handbook on NMR Crystallography (ISBN 9780-470-69961-4).

\section{F. Taulelle, Chair}

\subsection{Commission on Powder Diffraction}

2015 was a relatively quiet year. As usual there were a number of requests to support applications for IUCr sponsorship. Some of these were from familiar meetings and schools (e.g. Durham Powder Diffraction School, EPDIC and Size-Strain) and others were first-time applications via the CPD (e.g. 2nd North African Crystallographic Conference and Peruvian Course on Methods of Analysis of Polycrystals by Xray Diffraction). With other supported meetings in 2015 the geographical spread was better than in some past years.

Discussions continued via e-mail regarding the Rietveld refinement guidelines with different viewpoints as to the desirability of a supporting round robin. The lack of a physical meeting in 2015 hindered this somewhat but the EPDIC meeting in 2016 will provide a suitable opportunity to push this forwards.

Volume $\mathrm{H}$ of International Tables is in the final stages before publication. It is hoped that this long-delayed and lengthy volume will provide a good base source of information for all aspects of powder diffraction. As one of the authors I am very much looking forward to seeing it in print in 2016.

As the other Commissions can attest, preparations for the Hyderabad Congress in 2017 actually started in 2015 with the nomination of people for the International Programme Committee and early discussion of programme topics. The Commission was fortunate that a number of highly qualified individuals volunteered for the task.

\section{P. Whitfield, Chair}

\subsection{Commission on Small-Angle Scattering}

Commission meetings and communication. In addition to the normal communications by e-mail or during personal meetings at other national and international conferences, the triennial SAS meeting (SAS2015, Berlin, Germany) provided a special opportunity for members and consultants to the Commission (CSAS) to meet face-to-face for discussions and an open meeting of the Commission was held on 15 September with the following agenda:

Brief overview of recent Commission activities - Jill Trewhella;

Developments with regard to SAS and structural biology modelling with hybrid data - Jill Trewhella;

Developments of the extended sasCIF for easy data structural biology data exchange - Dmitri Svergun;

Update on canSAS - U-Ser Jeng;

The NIST SAXS intensity standard - Andrew Allen; IUCr SAS web site development - Jill Trewhella;

SAS2021 and encouraging bids - Jill Trewhella;

Other business (including items proposed from the floor).
Most of the CSAS members and consultants contribute to the various activity categories on an ongoing basis. What follows is a summary of highlights for 2015 .

Commission activities. A major highlight for our community in 2015 was the 16th meeting of Small-Angle Scattering, SAS2015, held in Berlin, Germany, 13-18 October, with conference co-Chairs Michael Gradzielski and Matthias Ballauff and with Peter Fratzl as Programme Chair (https:// www.helmholtz-berlin.de/events/sas/index_en.html). The conference had the strong participation and support from CSAS members and consultants with Daniel Clemens from the Organizing Committee acting as the principle liaison for CSAS and ensuring excellent communication and coordination of joint activities. Andrew Allen, Duncan McGillivray, Elliot Gilbert, Jan Skov Pedersen and Jill Trewhella served on the International Advisory Board and Dmitri Svergun served on the Scientific Programme Committee. The conference attracted 424 delegates from Europe, Eurasia, Asia and the Americas, who submitted 514 abstracts for oral presentations, posters and flash talks across a broad range of topics, including the most recent progress in instrumentation and data analysis and their applications in biology and materials science.

A special initiative of the CSAS led by Elliot Gilbert and USer Jeng was to organize a forum on Stimulating Industrial Interactions: Challenges, Barriers and Opportunities for Application of Small-Angle Scattering to Industry at SAS2015, Berlin. Three speakers were selected to discuss their personal experiences of working in an applied environment: Ron Jones (NIST), Lise Arleth (University of Copenhagen) and Kazuo Sakurai (University of Kita Kyushu). The session was followed by a highly interactive panel discussion where the audience had the opportunity to ask questions.

The IUCr co-sponsored Guinier Prize was awarded, on recommendation from a joint CSAS/SAS2015 Committee, to Professor Sow-Hsin Chen for his many contributions to the field of small-angle scattering methods development and applications in fundamental studies of soft condensed matter (see announcements at https://www.helmholtz-berlin.de/ events/sas/awards/index_en.html and http://www.iucr.org/ news/notices/archived/announcements/2014/2015_guinier_award).

Plans for a SAS2015 Special Issue of the Journal of Applied Crystallography were set up in 2015 (with advice from Elliot Gilbert, SAS2012 Conference Chair) with Andrew Allen (CSAS and $J A C$ Editorial Board) and Michael Gradzielski (SAS2015) serving as Guest Main Editors. Following initial publication of papers associated with the SAS2015 Conference in $J A C$ in late 2016 and early 2017, the selected papers will be collected together and the SAS2015 Special Issue published in Spring 2017.

SAS2018 will be held in Traverse City, USA, and the normal timeline would have had the site selection for 2021 voted on by the attendees at SAS2015. However, no bids were received in time for evaluation at the meeting and so members of CSAS with present, past and future SAS meeting organizers met to decide (1) how to encourage bids in a fair and open way and (2) to agree a process that would honour the tradition of 
conference attendees voting on proposal bids and as an important input to the joint CSAS/SAS meeting Evaluation Committee. With regard to the first objective, it was put to and agreed with the attendees of the meeting that:

The proposal bid Evaluation Committee and criteria will be as previously announced (https://www.helmholtz-berlin.de/ events/sas/bid/index_de.html);

The deadline for submission would be extended to 1 February 2016;

The members of the Evaluation Committee would actively encourage bids from regions that have not recently hosted but where there are relevant developments and SAS communities.

Three competitive proposal bids (two from Asia, one from South America) have been received. The next steps as agreed at SAS2015 by the attendees are:

The bids to be made available online to the SAS community for review, discussion and voting via the internet with communications managed through the SAS list-server. Voting will be by those who attended either SAS2012 or SAS2015, and voters will be requested to note their attendance.

The results of the voting will be provided to the Evaluation Committee who will make the final decision.

All are encouraged to sign up to the SAS list-server to receive news of the bids and more: go to http://www.iucr.org/ resources/lists.

The joint CSAS/meeting Chairs Evaluation Committee includes: Andrew Allen, Jill Trewhella, Elliot Gilbert (SAS2012), Randall E. Winans, Pete Jemian, and Jan Ilavsky (SAS2018), Stephen King and Nick Terrill (SAS209), Matthias Ballauff and Michael Gradzielski (SAS2015), with Daniel Clemens (SAS2015) coordinating.

Finally, toward the end of 2015, CSAS evaluated and ultimately recommended support for the following meetings:

The 4th International Soft Matter Conference, held at Alpexpo, Grenoble, France, 12-16 September 2016. The ISMC meetings are consistently of high quality and well attended by the international community, including the SAS community.

The 12th International Conference on Biology and Synchrotron Radiation (BSR12), to be held at the SLAC National Accelerator Laboratory, 21-24 August 2016. The triennial BSR conferences have a long-standing record as being a very successful forum for bringing together the scientists involved in the methodical developments on synchrotron and laser sources with a broad community of biologists having an ambition to make the best use of the most advanced infrastructures in structural biology.

Educational activities. In 2015, CSAS members and consultants contributed to and organized a large number of courses, tutorials and lectures to improve awareness of SAS methods and applications, and also to increase the expertise in SAS and its applications broadly.

The European Molecular Biology Organization (EMBO)supported Global Exchange Lecture and Practical Courses are growing in popularity among those aspiring to learn about SAS applications in structural biology. A feature of these is that they generally do not focus exclusively on SAS, rather they place SAS in the context of what have been traditionally more main-stream techniques, including crystallography, and thus are able to emphasize the complementarity of SAS among the suite of modern structural biology tools. Courses that were held or planned for in 2015 included:

EMBO Global Exchange Lecture Courses with a focus on SAS:

At a Small-Angle Neutron and X-ray Scattering from Proteins in Solution Course (Grenoble, France, 18-22 May 2015) Jill Trewhella, Dmitri Svergun and Bente Vestergaard contributed talks.

An EMBO-supported Global Exchange Lecture Course on Structural and Biophysical Methods for Biological Macromolecules in Solution was organized in Taipei, 4-10 May 2015, with Dmitri Svergun the main organizer and U-Ser Jeng one of the main local organizers. Here, SAXS and SANS were presented as part of the hybrid approach in structural studies. Sixty applicants were selected from a highly competitive list of 143 applicants. In the end, 56 participants attended the course, including three industrial participants. Of these, 28 participants were based in Taiwan, 16 were based in the Asia-Pacific region, 9 were based in Europe and 3 in North America. Fifteen tutors (10 European/Australian including CSAS Jill Trewhella and Bente Vestergaard, and 5 domestic from Taiwan) contributed 27 lectures and hands-on tutorials. The course finished with a workshop where selected students presented their own research.

Successful applications were made for an EMBO-supported Global Exchange Lecture Course in Korea (June 2016) and for an EMBO Practical Course on Solution Scattering from Biological Macromolecules (Hamburg, Germany, October 2016) (Dmitri Svergun main organizer) and The Structural Characterization of Macromolecular Complexes (Grenoble, France, May 2016) (Jill Trewhella to contribute Keynote talk).

With a focus on the growing SAS community in Scandinavia, Bente Vestergaard gave lectures at the Applications of $\mathrm{X}$-ray and Neutron Scattering in Biology, Chemistry and Physics course for students in the Øresund region [primarily Copenhagen (Denmark) and Lund (Sweden) Universities].

CSAS members from the Asia-Pacific region were very active promoting SAS methods and teaching the required skills to students and researchers in the region. In particular:

U-Ser Jeng organized SAS courses for the 2015 Asia-Pacific Edition of HERCULES at the National Synchrotron Research Center (NSRRC), Taiwan, 6-25 July 2015, and gave invited talks for SAS promotion in several local Universities, and in the workshop canSAS-VIII, at J-PARC, Tokai, Japan, 14-16 April.

Toshiji Kanaya gave a series of invited lectures: on neutron scattering including SANS at the annual meeting of the Chemical Society of Japan in March 2015; on polymer thin films by neutron scattering at the Gordon Conference on Neutron Scattering held in Hong Kong in June 2015; at the Asia-Oceania Conference on Neutron Scattering (AOCNS2015) held in Sydney, Australia, in July 2015; at the 5th Asian Symposium on Advanced Materials: Chemistry, Physics and Biomedicine of Functional and Novel Materials, 
in Korea in November 2015; and in Jülich for Soft Matter Days 2015, in Germany, in November 2015.

Expanding our educational activities to Turkey, U-Ser Jeng also presented SAS talks at two workshops in Denizli and Ankara (Pamukkale University and Hacettepe University) on Nanoscopic Analyses on Industrial Materials in November 2015.

For the Russian research community, V. Volkov was very active in contributing SAS expertise to training courses and providing a total of 26 specialist lectures and 10 training courses, with a number focused on condensed-matter applications and nanoscience, including:

A new 32-hour lecture course was prepared: Neutron Scattering in Investigation of Structure of Disordered Matter.

The 32-hour lecture course on Supra-Atomic Structures in Nanomaterials was extended by consideration of practical aspects of application of small-angle scattering methods and given to the students from the Institute of Nuclear Physics of Moscow State University.

A short six-hour lecture course Mathematical Methods in Small-Angle Scattering Data Treatment was given to the students from several physics institutions in Russia.

A ten-hour course of lectures on SAS methods was given to students from Moscow State University in the framework of the course X-ray Methods for Investigation of Matter.

A training course on SAXS instrumentation and data treatment was held for young scientists from several institutions.

Community-building activities. CSAS members and consultants served on various SAS-related committees and panels and editorial boards in 2015:

Andrew Allen continues as one of the three main Editors of Journal of Applied Crystallography, with Elliot Gilbert, Gernot Kostorz and Dmitri Svergun as Co-editors.

Dmitri Svergun is a member of the Associate Editorial Board of the Frontiers in Molecular Biosciences section of Structural Biology.

Jill Trewhella serves as a Co-editor (biology and medicine) for IUCrJ.

Consultant activities. Several CSAS members and consultants served on SAS-related standards development projects, and proposal and design evaluation committees:

Andrew Allen served as a technical consultant for the new ISO 17867:2015 SAXS (best practice) international standard: Particle Size Analysis - Small-Angle X-ray Scattering, developed in connection with particle-size measurements by ISO/ TC 24/SC 4 Particle Characterization. Standard issued 1 May 2015; see http://www.iso.org/iso/iso_catalogue/catalogue_tc/ catalogue_detail.htm?csnumber $=45820$. ISO/TC 24/SC 4 has moved on to draft a possible SAXS-based surface area measurement standard.

Andrew Allen continued to interact with the canSAS effort in 2015 - acting as liaison with canSAS on SAS publication issues (i.e. IUCr journals), data and metadata requirements for SAS, NIST SRM (see below), and ISO standards activity (see above). This included a presentation by video link from NIST directly to the canSAS meeting in Tokai, Japan, entitled:
Data Deposition, Metadata, ISO Standards, Calibration Standards, Publication Standards for Small-Angle Scattering, on 15 April 2015.

David Babonneau continues to serve on Peer Review Committee 3: Matter and Material Properties: Structure, Organization and Characterization, Elaboration for BeamTime Allocation at SOLEIL synchrotron, France.

Vladimir Volkov continued to consult on SAS methods for scientists from scientific and engineering institutes in Russia and also referees SAS-oriented projects submitted to the Russian scientific funds.

Bente Vestergaard served as member of the Priority and Evaluation Committee (SAXS and crystallography beamtime) at EMBL-Hamburg (Germany).

Organizational activities. SAS Commission members and consultants served on several programme or organization committees for SAS-related conferences and workshops in 2015:

David Babonneau co-Chaired the 3rd International GISAS Conference (satellite meeting of the SAS2015 conference) held in Nice, France, 8-11 September 2015.

Elliot Gilbert served on the Organizing Committee for the Australia-Oceania Neutron Scattering Association Conference, held in Manly, Australia, 19-23 July 2015.

U-Ser Jeng worked with the SAS community in Taiwan to prepare a proposal to host SAS2021.

Toshiji Kanaya has been very active in organizational activities, particularly for the Asian SAS community. In particular, he organized the 7th Asia-Oceania Neutron Scattering Association (AONSA) Neutron School held in Tokai, Japan, 30 November - 4 December 2015 as a President of the school. In addition, he organized the annual meeting of the Advanced Soft Material Beamline (FSBL), SPring-8 (a dedicated SAXS beamline for industry-oriented polymer and softmaterials science) held in Kyoto, Japan, in January 2015; chaired the Steering Committee of Advanced Soft Material Beamline (FSBL) in April 2015; organized a sub-research group in FSBL dedicated to GISAS and educational meetings for industrial researchers; and organized a seminar on recent developments of scattering methods and electron microscopes for the Polymer Society in Japan in Tokyo, in May 2015. He also chaired the Steering Committee of Advanced Soft Material Beamline (FSBL) in April 2015.

Dmitri Svergun served on the Scientific Programme Committee of the 16th International Conference on SmallAngle Scattering, Berlin, Germany, 13-18 September 2015, and is a member of the Advisory Committee of the Biology and Synchrotron Radiation Conference (to be held 21-24 August 2016, in Stanford, USA).

Iris Torriani served as Chair for the organization of the First Latin-American Crystallographic Association (LACA) Meeting that took place in São Paulo, Brazil, jointly with the Brazilian Crystallographic Association, 7-11 September 2015. Work has begun on Statutes and By-Laws to establish the Regional Association with the aim of having them approved soon for the next LACA meeting that will take place in Mexico in October 2016. 
Bente Vestergaard and Dmitri Svergun co-organized the 61st Benson Symposium on Structural Biology on the Move, Copenhagen, Denmark, 24-27 August 2015, where the achievements within structural biology were highlighted, covering magnitudes of length scales, from high-resolution analysis to whole-cell imaging, with a prominent role for SAXS and SANS.

Vladimir Volkov served on the Committee for Small-Angle Scattering in Biopolymers, Petersburg State University, Russia, beginning 2015, and on the Organizing Committees of the Conference of the National Union of Crystallographers (to be held in Russia in 2016) and the III International Conference on Small-Angle Neutron Scattering (SANSYuMO, Dubna, Russia, 2016).

Technical activities. CSAS members continue to support the Worldwide Protein Data Bank (wwPDB) initiatives to establish a federated system of interconnected databases similar to what exists presently for the PDB (RSCB, PDBe, PDBj) but extended to include SAS data and models. The wwPDB SAS Task Force continues its work on requirements for biomolecular modelling (chaired by Jill Trewhella with Dmitri Svergun a member). As part of this effort, Dmitri Svergun's group maintained and curated the publicly available Small Angle Scattering Biological Data Bank (http://www.sasbdb.org), which reached over 300 deposited models during 2015. Following the wwPDB Hybrid Methods task force (HMtf) recommendations, the SAS extension for a Crystallographic Information Framework (CIF) has been extended [Kachala $e t$ al. (2016), J. Appl. Cryst. 49, 302-310], in collaboration with RCSB. Using the extended sasCIF, a process was started to relocate the SAS-based models from RSCB to SASBDB. In another development, a new version of the web server DARA for rapid search of structural neighbours using solution smallangle X-ray scattering data was made available to the community [Kikhney et al. (2016), Bioinformatics, 32, 616618].

Technical activities CSAS members and consultants took part in include:

Andrew Allen completed development of NIST standard reference material (SRM 3600) for SAXS intensity calibration, based on glassy carbon (in collaboration with others at NIST and at the Advanced Photon Source, Argonne National Laboratory). All documentation submitted to NIST SRM Office, September 2015; release of standard with final approval now scheduled for mid-2016.

Andrew Allen previously completed a chapter on heterogeneous materials for the new Volume $\mathrm{H}$ of International Tables for Crystallography. The chapter has been accepted but will be slightly updated and revised for final release.

U-Ser Jeng is leading a BioSAXS beamline project to design and construct a new dedicated high-brilliance biological SAXS/WAXS beamline at the new $3 \mathrm{GeV}$ synchrotron of the NSRRC, Taiwan.

Jill Trewhella and Dmitri Svergun continue as members of the Worldwide Protein Data Bank (wwPDB) Integrative and Hybrid Methods task force (IHMtf) that aims among other things to establish a federated system of inter- connected databases similar to what exists presently for the PDB.

Dmitri Svergun's group maintained and curated the publicly available Small-Angle Scattering Biological Data Bank (http://www.sasbdb.org), which reached over 300 deposited models during 2015.

Dmitri Svergun, in a collaboration between Dmitri Svergun and the Rutgers Center for Structural Biology (RSCB), and following the recommendations of wwPDB IHMtf, has further developed the SAS extension for a Crystallographic Information Framework (CIF). Using the extended sasCIF, a process was started to relocate the SAS-based models from RSCB to SASBDB. In another development, a new version of the web server DARA for rapid search of structural neighbours using solution small-angle X-ray scattering data was made available to the community.

Jill Trewhella and Dmitri Svergun continue as members of the wwPDB SAS Task Force with its focus on requirements for SAS data standards, biomolecular modelling and validation.

In summary, it is fair to say that the CSAS continued its busy and productive agenda for 2015 and we look forward to continuing supporting and promoting the application of SAS techniques in a broad range of scientific fields.

\section{J. Trewhella, Chair}

\subsection{Commission on Structural Chemistry}

The Commission was largely dormant for 2015, with the most significant development being the appointment of four nominees from the Commission on to the International Programme Committee for the 2017 Congress. Some discussion was held about a joint Microsymposium with the Commission on XAFS; however, it was felt within the Commission that it would have been of insufficient interest amongst the structural-chemistry community on the proposed topic. Nonetheless, we look forward to a great meeting in 2017 with a significant programme of structural chemistry.

\section{S. Batten, Chair}

\subsection{Commission on Synchrotron and XFEL Radiation}

Introduction. The aim of the Commission on Synchrotron and XFEL Radiation (CSXR) is to promote access and awareness of crystallographers worldwide to the world's synchrotron radiation (SR) and X-ray free electron laser (XFEL) facilities. To this end, the Commission broadly promotes the development of crystallographic instrumentation, technology and standards, and the synergies between storage-ring-based and LINAC-based next-generation sources such as X-FELs and Energy Recovery Linacs (ERLs). The bulk of the Commission's work is carried out via e-mail, with occasional face-toface meetings held at selected conferences attended by sufficient of the Commission members. 
Supported Meetings, Schools and Workshops. The Commission provided letters of support and endorsement for the following funding requests for meetings held during 2015:

The RapiData course on automated data collection held in April 2015 at the Stanford Synchrotron Radiation Laboratory, SLAC, USA, to support participation of Latin-American students;

13th School on Synchrotron Radiation, held 14-25 September 2015, organized by the Italian Synchrotron Radiation Society in collaboration with Elettra - Sincrotrone Trieste, to support the attendance of young scientists from Africa and the Middle East;

9th AOFSRR Cheiron School, organized by the AsiaOceania Forum for Synchrotron Radiation Research and held at SPring-8 in September 2015, to support the attendance of two students from Africa and the Middle East (see following report).

Asia-Oceania Forum for Synchrotron Radiation. The AsiaOceania Forum for Synchrotron Radiation Research is an international network whose mission is to foster collaboration among synchrotron-radiation facilities and user communities in Asia and Oceania, as well as promoting collaborations with facilities and communities in America and Europe. The eight facility-operating nations in the region are full members of the AOFSRR, and the Forum's mission includes promotion of synchrotron-based science throughout the region. To this end Malaysia, New Zealand and Vietnam are associate members of the AOFSRR. Several members of the Commission play active roles in the organization, including Youichi Murakami (current AOFSRR President), Richard Garrett (Executive Committee member and Treasurer).

One of the core activities of the AOFSRR has been the Cheiron School, a two-week international synchrotron school, which has been held annually at SPring-8 since 2007. The curriculum is very broad, covering both the fundamentals of synchrotron-radiation generation and the various applications, including all the common crystallographic applications. In 2015 the IUCr supported the attendance of two students, one each from the Middle-East and Africa, to the Cheiron School. The IUCr attendees were Dr Areej Abuhammad, an Assistant Professor at the School of Pharmacy, University of Jordan, and $\mathrm{Mr}$ Boudraa Issam, a $\mathrm{PhD}$ student from the University Mentouri Constantine, Algeria. This followed the attendance of three African students in 2014, supported as part of the International Year of Crystallography. Lecturers at the 2015 school included IUCr Executive Committee members Mitchell Guss and Masaki Takata, and CSXR Chair Richard Garrett.

The 2015 school was the ninth year that SPring- 8 has hosted this event. Following a review it has been decided to change the format of the SPring- 8 school to a shorter higher-level workshop aimed more specifically at staff members of the AOFSRR synchrotron facilities. The AOFSRR is currently considering re-launching the broader Cheiron school as an annual school rotating between the region's light sources.

12th International Conference on Synchrotron Radiation Instrumentation. The International Conference for Synchro- tron Radiation Instrumentation (SRI) is the premier conference series for the synchrotron and free-electron laser light source community worldwide. It is held every three years and the 2015 event was held in New York City, USA, hosted by the National Synchrotron Light Source II (NSLS-II). About 730 participants listened to two Keynote speeches, 12 Plenary talks and 31 parallel sessions. Several hundred posters were presented in three poster sessions. CSXR member Thomas Tscentscher served on the SRI2015 International Programme Committee.

The two Keynote presentations addressed recent advances in structure determination using crystallography at both synchrotron and XFEL light sources: multiple-length-scale problems from atomic to $\mathrm{mm}$ dimension were discussed by $\mathrm{M}$. Miller (Cornell), and H. Chapman (CFEL Hamburg) presented developments in serial crystallography using FEL and SR sources. Serial crystallography is a new technique for protein-structure determination that can be used when large, well-diffracting crystals are not available. The Plenary talks gave a wide cross section of instrumentation development of SR and FEL sources, both for the sources and for the sample environment and scattering techniques. Several areas showed particularly dynamic development. Examples are the development of area detectors for X-ray research, the improved mirror-optics schemes to reach smaller foci with full intensity, and instrumentation for X-ray FEL experiments.

Other activities. Members of the Commission are active in a number of roles with international committees and networks. Aside from SRI2015 and the AOFSRR, mentioned above in this report, examples include: Janet Smith serves on the Advanced Light Source Scientific Advisory Committee (SAC); Sakura Pascarelli serves on the Australian Synchrotron SAC; Maciej Kozak is President of the Polish Synchrotron Radiation Society and a member of Polish Synchrotron - a council supporting the construction of Polish synchrotron SOLARIS in Krakow; Soichi Wakatsuki serves on the NSLS II SAC and is Chair of the 12th International Conference on Biology and Synchrotron Radiation (2016); Richard Garrett is a member of the International Programme Committee of both AsCA2015 (Calcutta, India) and AsCA2016 (Hanoi, Vietnam).

\section{R. F. Garrett, Chair}

\subsection{Commission on XAFS}

The Commission (CXAFS) met at the XAFS16 conference in Karlsruhe, Germany, 25 August 2015. Present: Chris Chantler, Krystyna Jablonska, Giuliana Aquilanti, Farideh Jalilehvand, Pieter Glatzel, Masao Tabuchi, Bruce Ravel, Bruce Bunker, Federico Boscherini.

The present CXAFS members reported on performed and planned activities. Particularly, the activity regarding the International Tables for Crystallography, Volume I, was discussed in detail. C. Chantler, B. Bunker and F. Boscherini are the Editors. They completed the plan of the volume and invitations to submit chapters have been sent to many scien- 
tists. The first version of the volume should be completed in the first part of 2016. The planned activity regarding the preparation for the scientific programme for the Hyderabad Congress in 2017 was also discussed and approved.

CXAFS web page. G. Aquilanti and M. Tabuchi had the responsibility for the web site. The lectures of the XAS workshop held in Montreal have been uploaded to the web page. The information about the new members of the Commission has been updated. Photos of most of the members were uploaded. Updates in the XAFS beamlines section are being implemented. At the meeting during XAFS16 there was discussion about mirroring the site www.wayforlight.eu for the list of the European EXAFS beamlines. G. Aquilanti has decided to update the existing list as a careful analysis of the web site shows some discrepancies between the information given and the actual situation at synchrotrons. The information about forthcoming events is continuously updated.

Preparation for the Hyderabad Congress. F. Jalilehvand is the CXAFS liaison with the International Programme Committee of the Congress and is coordinating the activity. Four scientists have been proposed for Keynote Lectures from the EXAFS community. Two unshared and four unshared Microsymposia (MS) have been proposed.

F. Jalilehvand represented the Commission at the IPC meeting in Hyderabad and the outcome for our Commission and XAFS is outstanding. We will co-Chair or Chair eight MS, including all previously proposed MS + High Resolution Spectroscopy with SSRL.

Most excitingly, our Commission put forward several names as possible Invited Keynote Speakers. The Commission has never proposed Keynote or Plenary Speakers in past Congresses but has worked more towards strengthening the visibility of XAFS in MS. That this has been welcome and useful is seen by the outcome that two of our Keynote proposals are accepted as Invited Keynote Speakers for the coming Congress - a great demonstration of the recognition of new, advanced, and complementary techniques in the wider community.

IUCr XAFS Workshop. The next Workshop dedicated to XAFS for crystallographers will also be organized for the day before the Congress. The co-Chairs will be C. T. Chantler, B. Ravel and F. Javilehvand as IUCr liaison and local organizer. Responses from the IUCr and Congress Committees have been very favourable and invited speakers will be coordinated soon.

IUCr Congress Satellite with IXAS: Database Standards and Structures. The organization of the the second workshop on data standardization (Q2XAFS) to be held at Diamond, UK, as a satellite of the Hyderabad Congress was started by Sofia Diaz-Moreno as Chair of the workshop. Possible dates for the workshop are the 14 and 15 August 2017. It will be organized together with IXAS. C. T. Chantler and M. Newville (the new IXAS Executive Vice-President) will be co-Chairs.

$X A F S$ database. B. Ravel has worked on the database together with $M$. Newville. Numerous decisions have already been made, but there is still much to be discussed about how to organize this database, the structure of spectra and suggestions of definitions of formatted columns and entries.

Conference support and proposals. An application for support of the Conference Biology and Synchrotron Radiation to be held 21-24 August 2016 and hosted by SLAC National Accelerator Laboratory was submitted to the IUCr.

International Tables for Crystallography Volume I: XAS. Chantler and Boscherini are heavily involved in this as two of the three Editors, with Bruce Bunker, ex-Chair of IXAS. All of the Commission is involved in this extensive activity. Currently some 100-150 experts have accepted invitations to write specific advanced chapters and several have completed their drafts using the IUCr template. These are about to be sent to expert referee panels for review. All chapters will be fully reviewed in a normal journal peer-review process. The interest across the world experts in different sections and topics augurs very well for an excellent outcome, though much more work will be needed over the next 6-12 months.

\section{T. Chantler, Chair, and K. Jablonska and G. Aquilanti, Secretaries}

\section{Sub-committee on the Union Calendar}

The Sub-committee receives and considers requests for IUCr sponsorship and nominal financial support, and makes recommendations to the Executive Committee. Acting on the recommendations made by the Sub-committee, during 2015 the Executive Committee approved sponsorship of various schools and meetings, mostly with financial support. Those held in 2015 are listed at the beginning of this Report of the Executive Committee. Those scheduled for 2016, but approved in 2015, are listed below.

BioXFEL STC, San Juan, Puerto Rico, 13-15 January 2016. Macromolecular Crystallography School 2016: From Data Processing to Structure Refinement and Beyond, São Carlos, Brazil, 3-12 April 2016.

Powder Diffraction and Rietveld Refinement School, Durham, UK, 10-14 April 2016.

Crystallography for Space Sciences, Puebla, Mexico, 17-30 April 2016.

RapiData 2016, Stanford, USA, 24-29 April 2016.

6th Meeting on X-ray and Other Techniques in Investigations of the Objects of Cultural Heritage, Krakow, Poland, 1921 May 2016.

5th International School on Crystallization: Drugs, Foods, Agrochemicals, Minerals, New Materials, Granada, Spain, 2227 May 2016.

High-Pressure Crystallography: Status Artis and Emerging Opportunities, Erice, Italy, 27 May - 5 June 2016.

11th USPEX Workshop on Evolutionary and Interpretative Methods for Discovering the Structures and Rationalizing the Properties of Crystalline, Surface and Nanoparticle Materials, Lake Como, Italy, 5-9 June 2016. 
ED-XPD Workshop - Combining Electron and X-ray Powder Diffraction Techniques for Structural Characterization, Stockholm, Sweden, 6-10 June 2016.

15th European Powder Diffraction Conference (EPDIC15), Bari, Italy, 12-15 June 2016.

2016 Kuo Symposium on 3D Cryo-EM Molecular Imaging and 9th K. H. Kuo Summer School on Electron Microscopy and Crystallography, Beijing, People's Republic of China, 2429 June 2016.

7th European Charge Density Meeting (ECDM7): Latest Advances in Methodology and Applications of Charge Densities, Warsaw, Poland, 26 June - 1 July 2016.

International School on Fundamental Crystallography with Applications to Electron Crystallography, Antwerp, Belgium, 27 June - 2 July 2016.

ICCBM16 - 16th International Conference on the Crystallization of Biological Macromolecules, Prague, Czech Republic, 2-7 July 2016.

3rd International School on Aperiodic Crystals, Antwerp, Belgium, 4-9 July 2016.

16th International Summer School on Crystal Growth (ISSCG-16), Shiga, Japan, 1-7 August 2016.

18th International Conference on Crystal Growth and Epitaxy (ICCGE-18), Nagoya, Japan, 7-12 August 2016.

International School on Charge and Spin Density: From Experimental Determination to Interpretation, Nancy, France, 24-27 August 2016.

Organizers of meetings wishing to seek IUCr sponsorship should submit applications at least nine months in advance of the meeting, writing to the Chair of the Sub-committee. For up-to-date contact information, application procedures and rules, see http://www.iucr.org/iucr/sponsorship/meetings.html.

Requests from satellite meetings may be submitted, and possible financial support requested, separately or through the Organizing Committee of the main meeting.

Meetings (other than satellite meetings) scheduled to be held within one month before or after an IUCr Congress will not be considered for sponsorship. For any meetings scheduled to be held between one and two months before or after a Congress, the application for sponsorship will be sent to the Chair of the Congress Programme Committee for approval, or otherwise. For meetings (other than satellite meetings) scheduled to be held, in the respective region, within one month before or after a meeting of a Regional Associate (American Crystallographic Association, Asian Crystallographic Association, European Crystallographic Association, Latin-American Crystallographic Association), the applicants for sponsorship must seek approval of the Chair of the Regional Associate Organizing Committee.

IUCr sponsorship can only be given to meetings that are international in character and open to participants from all countries. For international meetings the membership of the Programme Committee is a good indication of this. National meetings are only supported if held in developing countries.

Explicit support from the relevant IUCr Commission(s) is required for any international meeting (except for the meetings of Regional Associates) and from the Commission on
Crystallographic Teaching for any international schools (except for those organized by an IUCr Commission).

The IUCr continues to support and uphold ICSU's policy of non-discrimination and adheres to its decisions and procedures concerning the free circulation of scientists. Organizers of any meetings seeking IUCr sponsorship or support must assure the Sub-committee on the Union Calendar that the authorities of the country in which the meeting is to take place guarantee free entrance of bona fide scientists from all countries.

Visiting Professorships. The IUCr Visiting Professorship Scheme aims to support some of the costs of having internationally recognized scientists as lecturers for short courses at workshops or schools organized in developing countries. These schools or workshops may have national or international character. Up to a maximum of three Visiting Professorships can be granted for a single event. Travel and insurance costs will be met by the IUCr, while the local organizers cover the accommodation/subsistence expenses. Visiting Professorships can be requested in conjunction with the application for IUCr funding of a meeting, or independently as a single action to obtain highly qualified international teaching support within a teaching programme of local character. Support from at least one IUCr Commission is required. Full details may be found at http://www.iucr.org/iucr/ sponsorship/vp.html.

\section{Committee for the Maintenance of the} Crystallographic Information File Standard (COMCIFS)

COMCIFS is tasked with maintaining and developing the Crystallographic Information Framework (CIF) on behalf of the IUCr. 2015 was a time of consolidation of the work performed over the last decade upgrading the standards underpinning CIF. Two important papers were accepted for publication in the Journal of Applied Crystallography, one describing the new CIF2 syntax standard [Bernstein et al. (2016), J. Appl. Cryst. 49, 277-284], and the other companion paper describing a freely available C-language programming library for reading and writing CIF files in both old and new formats [Bollinger (2016), J. Appl. Cryst. 49, 285-291].

A revised edition of International Tables Volume G documenting the new standards is in preparation.

New dictionaries. No new dictionaries were published in 2015. Work continued within the Commission on Magnetic Structures concerning the datanames that will appear in the final magnetic CIF dictionary.

Interaction with other data-management initiatives. COMCIFS members were active participants in the Diffraction Data Deposition Working Group workshop held as a satellite of the European Crystallographic Meeting in August. Metadata associated with high-pressure experiments were presented and discussed, and a CIF dictionary for this field is planned.

Starting in 2012, COMCIFS and the NeXus International Advisory Committee (NIAC) launched a joint effort to 
achieve interoperability between imgCIF and NeXus in order properly to support the new generation of pixel array detectors, especially the Dectris Eiger detector that writes its output as HDF5-based files. In 2015 the effort saw its first practical applications for the first Eiger 16M detectors. These detectors write NeXus/HDF5 files, but most existing processing software for macromolecular crystallography requires imgCIF-based $\mathrm{CBFs}$, so the initial uses of the Eiger $16 \mathrm{M}$ have required translation of all images from NeXus/HDF5 to imgCIF/CBF. A member of COMCIFS, Herbert J. Bernstein, has been a member of NIAC since 2012 and his participation in NIAC as representing CIF to NIAC has been confirmed by vote of NIAC. In addition, during 2015, NIAC deprecated its existing representations of detector and goniometer axes, and adopted a new presentation based on the mmCIF AXIS category. Continued progress is expected.

Future plans. As decided in Montreal, current DDL1 dictionaries should be transformed to the new DDLm standard, starting with the core dictionary. Together with development of tools for the new standards, this is likely to consume most of the available time of COMCIFS members and dictionary-management groups in the coming year. Workshops are also planned in order to train CIF software developers and users in the new standards.

\section{J. Hester, Chair}

\section{IUCr Newsletter}

Three issues of Volume 23 were produced in 2015. All three issues were 24 pages in length. As in previous years, the content covered topics such as activities of the IUCr, its Regional Associates and Commissions, IYCr2014 activities, letters to the editor, news concerning crystallographers and crystallography in general, awards, book reviews, election results, resources, meeting reports, obituaries, future meeting announcements, and a general meeting calendar. A link to a readers survey ran in all the issues.

Each issue carried a President's column written by Marv Hackert and an editorial by Jonathan Agbenyega. Bill Duax handled all editorial responsibilities. Patti Potter was responsible for layout and all phases of production and distribution.

Each issue devoted two pages to articles related to $\mathrm{IUCr}$ journals. All three issues contained several pages of articles pertaining to IYCr2014, and issue 1 contained reports from the Montreal Congress.

Additional meeting and workshop reports were published covering activities in Brazil, Croatia, France, Italy, Poland, Slovenia, Spain, Switzerland and the UK. Future meeting announcements included the Hyderabad Congress as well as meetings in Croatia, Germany and Switzerland.

Distribution was done electronically for all three issues. Messages were sent to an average of 12668 people for the electronic version. Print copies went to an average of 560 libraries and individuals, and copies went to several meetings, including the annual meetings of the Regional Associates.

W. L. Duax, Editor, and P. Potter, Production Manager

\section{IUCr/Oxford University Press (OUP) Book Series}

In 2015, the cooperation between Oxford University Press (OUP) and the IUCr/OUP Book Series Selection Committee was more productive than in 2014, when no book was published.

A history book has been published:

Crystal Clear. The Autobiographies of Sir Lawrence and Lady Bragg, by A. M. Glazer, Patience Thomson, published 23 July 2015.

A new volume has been published in the Texts on Crystallography series:

Basics of Crystallography and Diffraction, Fourth Edition, by Christopher Hammond, published 11 June 2015.

In addition the history book Early Days of X-ray Crystallography, by André Authier was republished in paperback 29 October 2015.

A number of new books are in the production phase and others are in the pipeline. The Committee and the OUP editing staff reviewed a number of proposals and there are contacts with authors about possible new volumes.

The Committee is very interested in proposals for new volumes and encourages prospective authors to contact the Chair of the Committee (davide.viterbo@mfn.unipmn.it). Readers may suggest topics and/or authors, as they know the subjects that are not well covered in the literature. Manuscripts covering important aspects of crystallography and related fields are very welcome.

D. Viterbo, Chair of IUCr/OUP Book Series Selection Committee

\section{Regional Associates and Scientific Associates}

\subsection{American Crystallographic Association (ACA)}

The American Crystallographic Association, Inc. (ACA) is a non-profit, scientific organization of more than 1200 members. The ACA was founded in 1949 through a merger of the American Society for X-ray and Electron Diffraction (ASXRED) and the Crystallographic Society of America (CSA). The objective of the ACA is to promote interactions among scientists who study the structure of matter at atomic (or near atomic) resolution.

The 2015 ACA Council consisted of Christopher Cahill (President), Tom Terwilliger (Vice-President), Martha Teeter (Past-President), S. N. Rao (Chief Financial Officer and Interim Treasurer), Jim Kaduk (Treasurer), Diana Tomchick (Secretary) and Yulia Sveryugina (ex officio), as Young Scientists Special Interest Group (YSSIG) representative. Michael James serves as the Canadian National Committee for 
Crystallography (CNCC) representative, Bill Duax as Chief Executive Officer, Marcia Colquhoun as Executive Secretary and Hanna Dabkowska as the IUCr representative. The Council met three times in 2015.

The ACA 65th Annual Meeting in 2015 was held in Sheraton Downtown Hotel, Philadelphia, 25-29 July. It was attended by 656 participants, with many first-time attendees. 448 abstracts were submitted. The educational impact of this and future meetings was hailed as extremely important.

About 40 exhibitors (including the IUCr) participated in the Exhibit Show. The event was sponsored by 24 organizations, including the IUCr and AIP Publishing and it generated some income.

The Programme Chairs were Louise Dave and Kraig Wheeler. Yulia Sevryugina and her fellow young scientists were all responsible for outstanding sessions and great social events.

The 2015 ACA Award winners were Laurence Marks (Warren Award), Greg Petsko (Buerger Award) and Yan Jessie Zhang (Etter Early Career Award). This year the recipient of the ACA Service Award was Ilia Guzei.

Judith Kelly, who is the CSSP Secretary and the ACA Representative to CSSP, submitted an extensive Council of Scientific Society Presidents (CSSP) report to the ACA Council.

More information about the Philadelphia meeting and details about the programme and about three adjacent workshops can be found at http://www.amercrystalassn.org/ 2015-mtg-homepage.

The 2016 (66th) Annual Meeting will be held at the Sheraton Hotel in Denver, Colorado, 22-26 July. Amy Sarjeant (Northwestern University) and Eddie Snell (Hauptman Woodward MRI) are the Programme Chairs.

The 2017 (IUCr Congress Year) Annual Meeting will be held at the Hyatt Regency Hotel in New Orleans, Louisiana, 26-30 May. Yulia Sevryugina and Ilia Guzei have agreed to be co-Chairs for this meeting.

The 2018 Annual meeting will be held 20-24 July in Toronto, Ontario, Canada.

The IUCr and the ACA. IUCr President Marvin Hackert met with the ACA Council during the Philadelphia Meeting. $\mathrm{He}$ discussed the IUCr activities updates for after-the-IYCr time. He highligted the services which may be provided to the Regional Associates (if requested) by the IUCr. These would include providing web-site updates and managing its content (also for a Newsletter); advice in publishing, improving the World Directory of Crystallographers and providing the help of a financial officer. The IUCr could also provide services such as organizing conferences, workshops, fund raisings, collecting dues and bookkeeping. It is essential that the ACA knows about these possibilities, it does not have to use them. The Council reaction was to wait until they see more of the proposal and then have conversations about services the IUCr could provide for the ACA. It was suggested that at the Denver meeting the ACA Council and the IUCr Executive Committee should meet and discuss what could be done. If so, this meeting (about two hours or even an evening reception) should be put on the agenda. It was suggested that a list of potentially useful services should be compiled, presented to the IUCr and compared with an IUCr offer. The costs of these services has to be discussed on the assumption that the proposal does not mean pulling the money from the Regional Associates.

The IUCr Newsletter would be handed over in 2017 from Bill Duax to the IUCr. There will be an Editorial Committee, and Bill has been given the option to be a part of that Committee, as he no longer wishes to be the Chief Editor (an essential position).

IYCr Legacy Meeting. Cora Lind-Kovacs and Ilia Guzei were ACA delegates to Crystallography for the Next Generation: the Legacy of IYCr, organized in Rabat, Morocco, 22-24 April 2015. They both have been very active in outreach activities in IYCr and both are committed to enhancing crystallography's image in the USA.

Hyderabad Congress. The letter from Gautam Desiraju 'Why participate in IUCr2017?' was submitted to the Council and it will be published in the next edition of $A C A$ Reflexions.

AIP and the ACA. Chris Cahill was - until September 2015 - the ACA member representative to American Institute of Physics (AIP, a corporation with 10 member societies and an annual budget exceeding USD 70M). Tom Terwilliger took over from him. In his report Cahill discussed how the ACA can best exploit the resources available through the AIP, including Media Services, which produce a very high quality news releases in Inside Science (http://www.insidescience.org/), production (for a cost) of promotional materials associated with ACA annual meetings, assistance with logistics, access to the Center for Physics Resources etc. Physics Today - in paper version - is regarded as a very valuable asset available regularly and free for ACA members. Cahill stressed that there is a potential for a new and better relationship between the ACA and AIP.

B. Robert Brown, who has recently replaced Fred Dylla as the CEO of the AIP, and Judith Flippen-Anderson (AIP Corporate Secretary) both met with the Council during the Philadelphia meeting and discussed plans for future collaboration.

Charlie Carter will continue as the ACA representative to the AIP Board of Directors.

Other ACA members that currently serve on AIP committees are Kraig Wheeler, Physics Education; Eddie Snell, News and Media; Krystle McLaughlin, Diversity; Virginia Pett, History.

Physics Today. The 2015 November issue outlines the benefit of being an ACA member, and the January issue is about the Denver meeting.

Structural Dynamics - ACA/AIP journal. The new ACA potentially profitable, online journal Structural Dynamics (http://sd.aip.org) is co-published with the AIP. It boasts an impressive average time of 76 days from submission to publication. Journal topics include structural dynamics of molecular systems, biological systems, solid materials, liquids and solutions, surfaces and interfaces studies using highly 
coherent sources. It is not bringing any profit to the ACA at this stage.

The Strategic Planning Committee consisting of Cheryl Stevens (Chair), Bill Duax, Judy Flippen-Anderson, S. N. Rao, Martha Teeter, George Phillips and Marcia Colquhoun has met a few times since its creation. The survey of the membership suggested that crystallographers would like to see more educational opportunities for members, reduction in the dues for joining the ACA and in the cost of conference registration, and an e-mail bulletin board that would be aimed at all aspects of crystallography, including small-molecule and powder crystallography.

Decisions have to be considered and implemented for the post Duax, Colquhoun and Rao era. The transition of CEO, $\mathrm{CFO}$ and Office Manager is an integral process that should begin long before the leaders leave, so the change of guards will be smooth and safe for the ACA. The most important issues to be dealt with are headquarters site selection and choosing dedicated full-time or part-time ACA CEO, CFO and Association Manager with familiarity, interest or expertise in crystallography. Excellent written statements regarding the Management of the Transition, ACA Succession and Sustainability by the CEO, a Succession Proposal for the $\mathrm{CFO}$ and a Succession Proposal for Headquarters in Buffalo were provided by Cahill, Duax, Rao and Colquhoun, respectively.

Another action item at the Council meeting was setting up a committee to develop a fund-raising plan for the ACA. As this is a major commitment and requires some intensive work from both the Council and the ACA, it will be discussed again.

Many of the named award funds have balances that are significantly higher than the recommended minimum amount (RMA) required for generating funds for the awards, while a few have balances lower than the RMA.

2015 ACA Fellows. This title recognizes a high level of excellence in scientific research, teaching and professional duties, but also service, leadership and personal engagement in the ACA and the broader world of crystallography and science.

Social media. The ACA now have presence on Facebook (American Crystallographic Association) and on Twitter and Instagram (ACAxtal).

The Canadian National Committee for Crystallography (CNCC) is undergoing major changes: the main office of the $\mathrm{CNCC}$ is to be located at the Canadian Light Source (in Saskatoon), the terms of reference agreement between NRC (the group that has been responsible for the CNCC and membership in the IUCr) are being updated, as are the roles of CNCC members in the future. The other issues deal with establishing a CNCC web site and with the management of the Larry Calvert Travel Fund. The new Chair of the CNCC is Patrick Mercier, the Vice-Chair is Tomislav Friscic, the Executive Secretary is Michel Fodje and the Treasurer is Brian Patrick. Their term will be three years.

\section{H. A. Dabkowska, IUCr Representative}

\subsection{Asian Crystallographic Association (AsCA)}

$A s C A$ 2015. The 13th Conference of the Asian Crystallographic Association was held at Science City, Kolkata, India, 5-8 December 2015. This is the second time the meeting has been held in India; the earlier occasion was in 2001 (18-21 November) at Bangalore. The meeting had about 393 participants (279 male, 114 female) from 26 countries, with the break-up among different countries being: Australia 36, Bangladesh 19, Brazil 1, People's Republic of China 10, France 2, Germany 4, Hong Kong 2, India 194, Ireland 1, Italy 1, Japan 46, Korea 12, The Netherlands 1, New Zealand 3, Nigeria 1, Saudi Arabia 2, Singapore 12, Sri Lanka 2, Switzerland 2, Taiwan 9, Thailand 2, UAE 1, UK 13, USA 13, Uzbekistan 2, Vietnam 2.

The International Programme Committee, led by Alice Vrielink, provided an intensive programme that covered all aspects of crystallography and the latest developments in techniques and software. The scientific session consisted of 4 Plenary talks (by Petra Fromme, Mohaned Eddaoudi, Kenneth Harris and M. Vijayan), 5 Keynote addresses (by Michelle Dunstone, Sue-Lein Wang, Michi Suga, Haitao Li and Parmial Bharadwaj), and 102 oral presentations distributed in 18 Microsymposia (MS1-18), two software sessions (CS1-2) and one General Interest session (GIS) on pharmaceuticals. There were about 180 poster presentations. A special AsCA Rising Star Session was held on the last day, where the six best abstracts submitted by young participants (PhD or early post-docs), as selected by a panel of judges, made a 15 min oral presentation of their work. This gave an opportunity to the promising young scientists to present their work and provide a boost to their scientific career. In addition, here were three IUCr Poster Prizes, three ASCA 2015 Poster Awards and one RCSB PDB Award.

About ten commercial sponsors exhibited at the meeting. Bruker made a worldwide launch of their product D8 Venture at the meeting. This is the first time that a product has been launched at an AsCA meeting. The IUCr supported the meeting generously, as did also many granting agencies from India and academic institutions and bodies.

The details of the scientific programme, the list of participants etc has been transferred to the AsCA web site (http:// asca.iucr.org/). In the AsCA Council Meeting it was decided that AsCA 2019 would be held in Singapore.

AsCA 2016. The 14th Conference of AsCA will be held in Hanoi, Vietnam (Venue: Hanoi University of Science and Technology, 4-7 December 2016): Chair of the Local Organizing Committee: Duong Ngoc Huyen (huyen.duongngoc@hust.edu.vn); Chair of the International Programme Committee: Masaki Kawano (mkawano@postech.ac.kr). The AsCA2016 meeting will consist of two parallel satellite meetings, eighteen Microsymposia, an education conference workshop on minerals and gems, crystallographic software sessions, a special section on materials and a Rising Star session by young scientists. The scientific scope of AsCA2016 will cover all important aspects of crystallography-related areas, including synchrotron/neutron, structural biology, 
chemical crystallography, materials and polymer science, crystal growth/crystallization, electron microscopy, informatics, and much more. Details are available at the conference web site (http://www.asca2016.org/).

\section{Takata, IUCr Representative}

\subsection{European Crystallographic Association (ECA)}

The main ECA event - ECM29 (29th European Crystallographic Meeting) - was organized in Rovinj, Croatia, 23-28 August, and was very successful. The programme was organized mainly into 50 sessions (6-7 in parallel) with typically five lectures per session. The organizers reported 785 scientific contributions and 1050 participants, which is one of the highest attendances for ECMs in the last 20 years. Previously, attendances of more than 1000 have only occured in Darmstadt (2010) (organized together with EPDIC), Nancy (2000) and Prague (1998). One third of the participants came from the UK and Germany. There were two Plenary Lectures, sixteen Keynote Lectures and quite a large exhibition with 32 exhibitors. The attendance of 55 students was supported financially. Altogether 12 poster prizes were awarded during the closing ceremony. Ten satellite meetings were organized, mainly close to the start of the conference and mostly focused on crystallographic software. An Electron Crystallography School took place in Porec after the conference. The traditional Young Crystallographers Mixer was included in the social programme.

ECM programmes are mainly prepared by twelve SIGs (Special Interest Groups) and two GIGs (General Interest Groups) and in recent years it has been organized according to five focus areas: Biological and Macromolecular Crystallography; Materials and Minerals; Physical Including Fundamental Crystallography; Chemical Crystallography; and Experimental and Computational Techniques. This procedure has been quite effective but of course cannot be completely perfect. At ECM29 two main ECA prizes were awarded. The 8th Max Perutz Prize was awarded to Professor John R. Helliwell, Emeritus Professor of Chemistry, University of Manchester, UK, for his 'long, generous and fruitful dedication to developing all aspects of the use of synchrotron radiation for crystallography and for his boosting support to global development of synchrotron and neutron facilities... He also has been constantly engaged in outreach and dissemination of crystallography to the scientific community'. The Seventh Erwin Felix Lewy Bertaut Prize of the ECA and ENSA (European Neutron Scattering Association) was awarded to Dr Giorgio Schiro from the Institut de Biologie Structurale of the CNRS, Grenoble, France, for his scientific contribution in the innovative scientific field of protein dynamics.

In Rovinj, there was also an ECA council meeting and a new ECA Executive Committee was elected: Alessia Bacchi (President), Andreas Roodt (Immediate Past President), Udo Heinemann (Vice-President), Georgina Rosair (Secretary), Christian Lehmann (Treasurer), Joke Hadermann, Marijana
Dakovic and Carl Henrik Görbitz (officers) and Fermin Otalora (education coordinator). Marijana Dakovic and Carl Henrik Görbitz are new members.

The regular winter Executive Committee meeting took place 13-15 February 2015, at the location of ECM30 in Basel, Switzerland. Since the IUCr Congress will be held in 2017, the winter meeting in 2016 was organized by the new ECA President in Parma, Italy, again in February. These are very intensive working meetings. The ECA Executive Committee considered the creation of an SIG on crystal growth and a GIG for teaching and education, perhaps also one for crystallography in art and archaeology. It also suggested that ECM satellite meetings should ask for support through the ECM. Discussion continues on how to strengthen the position of the ECA as a really European Association, which has some legal issues (now it is registered in The Netherlands according to Dutch law), and on the possibility of the use of professional management for the organization of ECMs.

The ECA is a member of ISE (Initiative for Science in Europe) - an independent platform of European learned societies and scientific organizations whose aim is to promote mechanisms to support all fields of science at a European level and it has been partially successful in scientific policy in Europe. The ISE meeting has been attended by the former ECA President Andreas Roodt and he recommended continuation of the ECA membership of this organization in the near future, in spite of the significant membership fee.

The ECA pays increasing attention to crystallographic education. The 2nd European Crystallography School was hold in Mieres (Asturias), Spain, 31 August - 5 September 2015, with the title Crystallography: Fundamentals, Online Tools and Applications. It was divided into four different modules: one day Pre-school, three days Fundamental Crystallography, two days Specific Subjects and one day Hot Topics (electron diffraction, synchrotron serial crystallography). There were 17 lecturers and 32 students. The students presented 27 posters. The school materials will be archived. The third school is being prepared by the Croatian Association of Crystallographers in Bol, Brac Island, Croatia, 25 September - 2 October 2016, and interests in holding the school in Poland and South Africa have been presented. The European Crystallography Master Program has been prepared. It is based on four semesters (120 credits). The students should come from widely different fields and have equally different scopes for their future work. So the structure of the master will include four different modules.

There are also activities in the Africa region. After the IYCr Legacy meeting in Rabat, Morocco, the Indaba 8 interdisciplinary workshop in South Africa was held. Unfortunately, the 2nd North African Crystallographic Meeting planned to be held in Tunisia had to be cancelled; however, the First Pan African Conference on Crystallography is being prepared for Cameroon, in October 2016.

The ECA has over 300 individual members (fee 10 EUR/ year), about 20 corporate members (fee 250 EUR/year), 33 national members and three observers. The income allows some support of schools and conferences. The main financial 
contribution is from the ECM. Collection of the individual membership fees was via credit card but transition to the PayPal system is now under way.

In previous years, the ECA has financially supported the Adhering Body of the IUCr's Regional Committee of Crystallographers from six countries from the ECA region. However, since three of these countries were accepted as full IUCr members by the Montreal General Assembly it was decided to not continue unless the remaining countries in the group and some other countries showed their own activity, organized themselves and asked for assistance. Attempts to involve countries like Armenia, Belarus, Estonia, Moldova, Romania, Lithuania, Bosnia-Herzegovina, Iran and Albania were not very successful. The OpenLab to be held in Albania in 2016 may perhaps help. There are still problems with Russian membership in the ECA.

The ECA supports schools or conferences with a budget of about EUR 7000 EUR. In 2015, EUR 8311 was provided. It was decided to distribute the support for attendance of young crystallographers at the ECM directly (via the ECA scholarship fund) rather than through a Bursary Committee of the ECM. Other conferences were supported as usual - XV BCA Intensive Teaching School in X-ray Structure Analysis (UK), the Erice School on Engineering Crystallography (Italy), the XVIII Conference on Electron Charge, Spin and Momentum Density (Sardinia, Italy), the Zürich School of Crystallography (Switzerland), the International School on Rietveld Refinement (Sofia, Bulgaria), the Second Balkan School on Fundamental Crystallography (Turkey) and the 3rd School on Crystal Structure Determination (Tunisia).

The ECA has two internet domains - http://crystallography.eu and http://ecanews.org - and has also created links in the main social networks [@social_eca (Twitter), ecanews (Facebook)].

A new ECA web site was introduced by Fermin Otaloro. It is using the Buddy Press plug-in and it is still under some development. It was suggested that a special area should be created there that was accessible only by ECA individual members.

The Executive Committee placed high attention on the preparation of ECM30, Basel, Switzerland, 28 August - 1 September 2016 at its Basel and Parma meetings. In Basel there was an inspection of the Congress Center. Organizers encouraged the Chairs and co-Chairs to invite two speakers per Microsymposium as usual. They also decided to use some software developed in Croatia for ECM29. They have succeeded in inviting two Nobel prize winners - Jean-Marie Lehn and Ada Yonath. Nine satellite meetings are planned.

The organization of the ECM31 was assigned to the Spanish Crystallographic Association with the location Oviedo, Spain, 22-27 August 2018 (Chair: Santiago Garcia-Granda). It will be organized in the Palace of Exhibitions and Congresses of Oviedo. A joint ECM-EPDIC16 meeting is suggested as there was a very successful joint ECM-EPDIC meeting in Darmstadt in 2010. However, the final decision will be mainly made by the EPDIC (SIG-8) Committee during EPDIC in June 2016 in Bari, Italy. The organizers also suggested a programme for families and their children in order to attract young crystallographers with families. There was a discussion in the Executive Committee about possible streaming of lectures, without definite conclusion.

ECM32 will take place in University of Vienna, Austria, in 2019 (Chair: Klaudia Hradil). Irish crystallographers are considering a bid for the ECM in 2021 and there is also interest from France.

\section{R. Kuzel, IUCr Representative}

\subsection{Latin-American Crystallographic Association}

During 2015, the most relevant activities of the crystallographic groups in Latin-American countries were to a large extent due to the exposure given to research in crystallography during the International Year of Crystallography. Meetings of the National Crystallographic Associations and local crystallography groups, national contests for primary/ secondary schools, OpenLabs subsidized by commercial enterprises, and diverse science-related forums took place in 2015, organized by several countries. A major event for the Latin-American Region was the First LACA Regional Meeting, which took place in São Paulo, Brazil, 9-11 September 2015, jointly with the 22nd Meeting of the Brazilian Crystallographic Association (ABCr).

The First LACA General Assembly gathered at the Auditorium of the Physics Institute of the University of São Paulo on 10 September 2015. The Agenda included key matters related to the formal organization of the association: (1) Statutes and By-Laws, (2) creation of a LACA fund, (3) general financial matters and operational budget (treasurer's accounting of present and future expenses), (4) elections of the new authorities, (5) periodicity of the LACA meetings, countries willing to host the next LACA meeting/possible date, (6) general matters. The following items were approved unanimously:

It was agreed that all country members that were already active members of the IUCr be automatically considered LACA members; this applies to the following Latin-American countries (Adhering Body): Mexico (Consejo Nacional de Ciencia y Tecnologia), Costa Rica [Centro Nacional de Alta Tecnologia (CeNAT)], Venezuela (Sociedad Venezolana de Cristalografia), Brazil (ABCr), Argentina (Consejo Nacional de Investigaciones Cientificas y Tecnicas), Uruguay (Academia Nacional de Ciencias del Uruguay) and Chile (Comision Nacional de Investigacion Cientifica y Tecnologia).

Professor Iris L. Torriani (Brazil) was nominated LACA's Provisional Treasurer.

A period of three years was established to complete legal status, call for general elections and organize meetings and admissions procedures.

Chile's proposal to organize the 2018 III-LACA Meeting was accepted.

Mexico's proposal to host the 2016 II-LACA Meeting was approved. 
More details of scientific, educational and promotional activities related to crystallography in several Latin-American countries during 2015 are reported below.

Mexico - SMCr. The last meeting of the Mexican Crystallographic Society was held in the Benemerita Universidad Autonoma de Puebla, Puebla, Mexico, 29 September - 1 October 2015. The IV National Diffraction Conference was held in Acapulco, Guerrero, Mexico 8-11 November 2015. As proposed in the 2015 General Assembly, the II-LACA Regional Meeting will take place in October 2016, in the city of Merida, Jucatan, Mexico.

Argentina - AACr. The XI Annual Meeting of the AACr was held in La Plata, 4-6 November 2015. The second edition of the International Crystal Growth Contest in Secondary Schools was held from April to November 2015. Four hundred schools from all over the country participated in this event. Thirteen prizes and 24 merit awards were granted. The VII AACr Crystallography School was held in La Plata and Buenos Aires, 23 October - 3 November 2015. The IV Workshop of the AACr: Users Meeting of Large Installations was held in La Plata, 7 November 2015. Teachers Training Courses on Crystallography and Crystal Growth were organized all over the country: 40 courses with a participation of over 1500 attendees (July to November 2015). The AACr sponsored the participation of Argentinian Schools in the international contest: Crystal Growth in Schools. Argentina received the largest number of distinctions: two gold medals and two bronze medals. Lectures and seminars were presented in several schools as well as Science and Technology Fairs, as part of an outstanding outreach effort on the part of several very active AACr members. In 2016 the AACr Annual Meeting, the satellite Workshop and the VIII Crystallography School will take place in the province of San Luis. The crystal-growth contests and other activities are planned to continue.

Brazil - ABCr. The XXII Annual Meeting of the ABCr, São Paulo, 9-11 September 2015, was held jointly with the First LACA Regional Meeting. The 2015 IUCr High-Pressure Workshop focused on high-pressure crystallography, and was organized as a satellite meeting of the LACA I Congress in São Paulo, 12-15 September 2015, held at the National Center for Research in Energy and Materials - CNPEM, Campinas, Brazil. A one-day ICDD Workshop on Powder Diffraction Techniques and Applications was held 8 September 2015, at the Physics Institute, UNICAMP, Campinas, SP, Brazil.

The XV edition of the Latin-American Seminar of Analysis by X-ray Techniques (SARX) will be hosted in the Imperial Museum (Petropolis, Rio de Janeiro, Brazil) 18-21 September 2016. The SARX event is an international meeting held in South-American countries and assembles the best researchers from around the world to promote the exchange of experiences in research and technology developments by X-ray techniques. Since 1997, SARX has taken place in many countries all over Latin America. The seminar is held every two years and the next will be in 2016, in Brazil. SARX-2016 will be organized by researchers of Rio de Janeiro State University (UERJ).
Uruguay - RUCr (Red Uruguaya de Cristalografia). The Macromolecular Crystallography School: From Data Processing to Structure Refinement and Beyond was a hands-on international workshop, held at the Institut Pasteur de Montevideo, Uruguay, 6-16 April 2015. The 2nd Crystal Growth National Contest (http://www.cncc.fq.edu.uy/) was organized by Facultad de Quimica, Universidad de la Republica and was funded by Agencia Nacional de Investigacion e Innovacion (PCTI_2014_13141). Silver and bronze medal prizes were obtained in the International Crystal Growth Competition in 2015.

Planned for 2016: second edition of the IUCr-UNESCO Bruker OpenLab Uruguay 2 (Resolución de Estructuras Cristalinas por Difracción de Rayos X de Monocristal), Montevideo, Uruguay, 23-29 February 2016.

Peru. Crystallography groups from Peru organized the II Peruvian Crystallography Congress and Course on Analytical X-ray Diffraction Methods for Polycrystalline Materials at the Universidad Nacional de San Marco, UNSM, Lima, 4-6 August 2015.

Costa Rica - (UCCr) Union Costarricense de Cristalografia (UCCr) (Costa Rican Union of Crystallography). No crystallographic meetings were reported for 2015, but the 7th Workshop on Green Chemistry and Nanotechnologies in Polymer Chemistry is being organized at the National Laboratory of Nanotechnology in San Jose, Costa Rica, 21-23 September 2016.

Venezuela - Sociedad Venezolana de Cristalografia (SVC) (Venezuelan Crystallographic Society). Most relevant crystallography groups in Venezuela, acting at the Venezuelan Research Institute (Instituto Venezolano de Investigacion Cientifica-IVIC), and the Universities of Los Andes (ULA), Central de Venezuela (UVC) and Simon Bolivar (USV) organized several events celebrating IYCr 2014 in different parts of the country. The 45th anniversary of the crystallography laboratory at the University of Los Andes was a special occasion for a major combined crystallographic meeting organized with the National Committee for Crystallography from Colombia. The International X-ray Diffraction Course (Rigaku OpenLab Colombia) took place in Bucaramanga, Colombia, 27-31 October 2014. Instructors and lecturers from Europe and the USA and young scientists from several neighbouring countries of the region and from Central America participated in the meeting.

Additional general activities: participation of the various National Committees in nominating members for the IUCr Commissions; Representation on the Programme Committee of the Hyderabad Congress.

An incentive was started for the creation of crystallography groups and for the organization of workshops and OpenLab meetings in countries that at present do not have formal crystallographic associations. During 2015 conversations began to organize events in Bolivia and Paraguay.

In summary, several important resolutions were taken during the First LACA Regional Meeting, which will contribute to the formalization of the structure of the LatinAmerican Regional Associate of the IUCr. The venues and 
dates of the next meetings and the final discussions of the Statutes and By-Laws were a start for further growth of the Association. The LACA-II Meeting in Mexico in 2016 will be fundamental in this respect. The activities reported in 2015 by the LACA countries clearly show how the International Year of Crystallography influenced the crystallographic community in Latin America; these activities will be important for many years to come.

\section{S. Garcia-Granda, IUCr Representative}

\subsection{International Organization for Crystal Growth (IOCG)}

No formal meeting of the IOCG (http://www.iocg.org/) was planned or organized in 2015.

The IOCG President for 2013-2016 is R. Fornari (Italy). Co-Vice-Presidents are T. F. Kuech (USA) and K. Kakimoto (Japan), the Secretary is H. A. Dabkowska (Canada), and the Treasurer is V. Fratello (USA). The members of the Executive Committee are J. M. Garcia-Ruiz (Spain), Y. Mori (Japan), K. Roberts (UK), M. Heuken (Germany), F. Puel (France), E. Vlieg (The Netherlands), Mu Wang (People's Republic of China) and J. De Yoreo (USA).

The connection with the Commission on Crystal Growth and Characterization of Materials (CCGCM) is evident, as T. F. Kuech, K. Kakimoto, E. Vlieg and J. M. García-Ruiz are also members/consultants of CCGCM.

The 18th International Conference on Crystal Growth and Epitaxy (ICCGE-18) will be held in Nagoya, Japan, 7-12 August 2016. Koichi Kakimoto, a member of CCGCM, will coChair ICCGE-18. Members and consultants of CCGCM are strongly involved in the work of the Programme and Advisory Committees of this meeting. As happened for ICCGE-17 in Poland, three symposia of the IOCG Conference will be officially co-organized by representatives of the IUCr, namely Janakiraman Kumar (Defect formation), François Puel (Industrial crystallization), Garcia Ruiz (Organic and biological crystallization). Detailed information about both the Conference and the School will be posted on the web sites http://www.iccge18.jp/index.html and http://www.iccge18.jp/ isscg16/index.html.

At the end of 2010 the European Network of Crystal Growth (ENCG) was constituted. Part of the scope of the ENCG is the organization of a European Conference on Crystal Growth (ECCG). After ECCG4 (held in Glasgow, UK, 17-20 June 2012), in 2015 the European Conference on Crystal Growth was organized in Bologna, Italy, and coChaired by myself. Also, the First European School on Crystal Growth was organized in Bologna. Many members/consultants of this Commission were involved in the organization of this Conference. These events were important to keep alive the tradition of crystal growth in Europe.

The next General Assembly of the IOCG will take place in Nagoya, Japan, during ICCGE-18.

\section{A. Zappettini, IUCr Representative}

\subsection{International Centre for Diffraction Data}

The Commission on Powder Diffraction maintains close links with the ICCD and also with the International X-ray Absorption Society (IXAS) (http://www.ixasportal.net/ixas/).

\section{P. Whitfield, IUCr Representative}

\subsection{Worldwide Protein Data Bank (wwPDB)}

The Worldwide Protein Data Bank is a formal Scientific Associate of the IUCr, which developed as a consortium of projects in North America (the RCSB PDB and the BMRB), Europe (PDBe), and Japan (PDBj) beginning in 2004. The Protein Data Bank (PDB) has been an essential resource for macromolecular crystallographers for more than 40 years. The IUCr in turn has helped shape its policies and its development. Accordingly, the IUCr has representation on the wwPDB Advisory Committee (wwPDB-AC).

The 2015 meeting of the wwPDB-AC was held on 2 October in Osaka, Japan. A new deposition and annotation (D\&A) system is now in use for all crystal-structure depositions. The new D\&A system is markedly more efficient, with the median time for completion of depositions reduced from 16.5 to 1.6 days. It also has improved ligand-annotation protocols and now has no limits on the size or complexity of structures that can be represented in a single file.

The Validation Task Force set up by the wwPDB for validation of crystal structures, headed by Randy Read, has begun working on an improved set of validation measures, paying special attention to ligands in crystal structures.

Much of the current development effort in the wwPDB involves extension of the D\&A system for use with the structures and data derived from NMR and cryo-EM analyses. The cryo-EM efforts are particularly urgent as the number of cryo-EM structures is beginning to increase rapidly. This need to extend the D\&A system was recognized at the meeting as the greatest current challenge for the wwPDB, and rigorous timelines have been set. [The wwPDB met its targets and the D\&A is now operating for both NMR and CryoEM structure deposition.]

Validation Task Forces led by Gaetano Montelione and Michael Nilges (NMR) and Richard Henderson and Andrej Sali (cryo-EM) have also been set up to establish validation tools and criteria for these structures. Good progress is being made. The protocols have a similar framework to those for $\mathrm{X}$-ray-derived structures but have necessarily different measures for analyzing fit to data.

The wwPDB also recognizes the increasing trend for models to be developed using hybrid methods, including (for example) small-angle scattering. For this reason a Task Force headed by Jill Trewhella has been set up to advise on the validation of SAXS data and another headed by Andrej Sali to advise on the issues posed by hybrid methods in general.

The vast majority (90\%) of structures deposited in the wwPDB, from the current total of 117000 , have been determined by X-ray crystallography, with NMR contributing $9 \%$ and cryo-EM $1 \%$. The role of the IUCr and its journals in 
support of the wwPDB is greatly appreciated and carries over to all deposited structures and data, whether determined by $\mathrm{X}$-ray methods or not.

It is also very pleasing to report that funding for all four partners in the wwPDB is stable, having been committed until 2017 for the PDB Japan (PDBj), until 2018 for PDB USA (RCSB) and until 2019 for PDB Europe (PDBe) and the NMR Data Bank (BMRB).

\section{E. N. Baker, IUCr Representative}

\section{Representatives on Other Bodies}

10.1. IUPAC Interdivisional Committee on Terminology, Nomenclature and Symbols (ICTNS)

There were no activities during 2015 that related to crystallography.

\section{P. Brock, IUCr Representative}

\subsection{International Council for Scientific and Technical Information (ICSTI)}

On 4 July 2015 there was a meeting of ICSTI in Hannover, Germany. This was an interesting meeting and led to a number of contacts who might be useful in future.

At the Annual General Meeting, ICSTI decided that membership fees should go up by $1.5 \%$. For the IUCr this means an increase to EUR 850 (IUCr is a category A member). Category B increases to EUR 1595. It was also decided that there will be a meeting in Philadelphia on 20 February 2016 (Annual Members Meeting) and the next AGM will be 9 or 10 September 2016 in Washington, USA.

At the meeting there were two workshops. The first workshop entitled ITOC (Information Trends and Opportunities Committee) was on Open Science and Open Data. The first speaker was Geoffrey Boulton (Edinburgh, UK) who gave an excellent talk on Open Data and the Future of Science, with examples of this in practice, including possible problems in open data (problems connected with industrial collaborators, for instance). Nonetheless, he expressed the view that publicly funded research at least should result in full public access to the data used in the research in future. The IUCr is already well there in any case. This talk was followed by three more, From Open Access to Open Science ( J. Cotta), Data Sovereignty VIVO Approach (L. Heller) and Legacy of the International Geophysical Year to the World Data System (M. Diepenbroek). There was a presentation of a number of online tools for measuring impact, READCUBE, OVERLEAF, ALTMETRIC and FIGSHARE.

The second workshop was by TACC (Technical Activities Coordinating Committee). Martin Fenner from PLOS (Germany) showed that the Public Library of Science requires all accepted papers to include a data-availability statement, and to make the data underlying the publication available as supplementary information or in a publicly available repository. Ben Mcleish and Stephen Cawley (UK) gave a joint talk tracking specific investigators using ALTMETRIC. They pointed out that systems like ALTMETRIC should be a boon for universities required to specify the impact of their research, such as the REF in the UK. Terri Mitton (France) talked about the data made available publicly by the OECD. Finally, Christian Soltmann described the European Patent System and claims that EPO contributes to innovation (he did not discuss the negative aspects of this, and was questioned about that).

At the subsequent ICSTI Executive Committee meeting there was a surprise. Attending the meeting was someone from Moscow who pointed out that there is another organization called ICSTI, supported by the UN, and managed from Moscow with about 38 member countries, including South Africa and India. He proposed some sort of joint linkage with our ICSTI and this was discussed in the Executive Committee after he left the room. A letter was later sent to him declining the invitation.

\section{A. M. Glazer, IUCr Representative}

\subsection{International Council for Science (ICSU)}

The International Council for Science (ICSU) is a nongovernmental organization with a global membership that includes 31 International Scientific Unions and 122 national scientific bodies representing 142 countries. As stated on its web site and in its annual report 'The long-term vision of the International Council for Science (ICSU) is for a world where excellence in science is effectively translated into policymaking and socio-economic development. In such a world, universal and equitable access to scientific data and information is a reality and all countries have the scientific capacity to use these and to contribute to generating the new knowledge that is necessary to establish their own development pathways in a sustainable manner.' The President of ICSU for 2014-2017 is Gordon McBean, a climate-change expert from Canada. Heide Hackmann became the new Executive Director for ICSU in March 2015 and works with a staff of about 18 in Paris. ICSU has three Regional Offices, serving Africa (Pretoria, South Africa), Asia and the Pacific (Kuala Lumpur, Malaysia), and Latin America and the Caribbean (Mexico City).

ICSU's strategic plan 2012-2017 identifies key priorities and associated activities that focus on three areas that resonate well with the interests of the IUCr: International Research Collaboration, Science for Policy, and the Universality of Science. In the area of International Research Collaboration, ICSU helps coordinate international research programmes. An example of these interdisciplinary bodies of particular interest to the IUCr are CODATA (Data for Science and Technology) and COSPAR (Space Research). ICSU also has been very active in Climate Research (improved understanding of global and regional climate changes), Disaster Risk (impacts of natural hazards), and Future Earth (sustainability), among others. Under Science for Policy, ICSU works to ensure that science is integrated into policy devel- 
opment. Under the priority of Universality of Science, ICSU seeks to address developing a truly global scientific community with a focus on capacity building, science education and access to data.

ICSU supported a Grants Programme that funded four projects in 2015. The IUCr was the lead applicant of one of the funded awards (with support from the ECA, UNESCO, SAASTA and Indaba) titled Building Science Capacity in Africa via Crystallography. The IUCr submitted the proposal on behalf of Andreas Roodt (ECA and Indaba) and Michele Zema (IUCr representative). The award provided EUR 30000 to support several conferences for capacity building of crystallography in Africa with a goal of cementing the African Crystallographic Association. The first of these was the Indaba conference held in South Africa in August 2015 with planned support for a North African conference, and the First Pan African Conference on Crystallography to be held in Cameroon in fall 2016.

ICSU launched Science International as a series of meetings to strengthen the voice of global science in international policy. This was done in cooperation with TWAS, IAP and ISSC. The first such meeting was held in December 2015 in Pretoria, South Africa, with a focus on Big Data and Open Data. A working group was formed to draft an accord on Open Data in a Big Data World, which is now available via the ICSU web site.

ICSU holds its General Assembly meetings every three years. It has been the tradition that the Immediate Past President represents the IUCr at ICSU. I was asked to start my representation early since Gautam Desiraju is very involved in planning for our next IUCr Congress in Hyderabad, India in 2017. I have also been appointed to the BISO committee, which is the arm of the NAS in the United States that seeks to improve cooperation with international organizations. I look forward to working with ICSU and representing the IUCr's interests in both these capacities.

\section{L. Hackert, IUCr Representative}

10.4. ICSU Committee on Data for Science and Technology (CODATA)

During 2015 planning has been advancing for the biennial CODATA conference SciDataCon 2016 (see http://www.scidatacon.org/2016/). This has the title Advancing the Frontiers of Data in Research, and will be a component of an International Data Week organized jointly by CODATA, the Research Data Alliance and the ICSU World Data System. It is to be held in Denver, USA, 11-16 September 2016. On behalf of the IUCr we proposed a Microsymposium on Crystallography and Structural Data Bases (http://www.scidatacon.org/2016/sessions/). This proposal has been accepted. The feedback received was interesting to the crystallographic community, which is cited specifically: All reviewers considered this an excellent important session proposal and important to include in the conference and in particular noted that 'other science domains have much to learn from this community'. Reviewers did observe that it was important that the session should go beyond the perspective of different crystallography databases to reflect on community-wide issues: 'If possible if would be good if two more papers could be included: one on how this community has managed systems over so many years and another on the crystallographers' work on time-stamped ontologies'.

CODATA have been developing a leadership document entitled Open Data in a Big Data World - An International Accord. This tackles various issues of open access to data and its ramifications. Of particular relevance to the IUCr are: it lays out the responsibilities and duties to be expected of publishers; it explains the approaches to be taken for data archives to be sustainable and open; it analyses the approaches being taken across the globe. A detailed IUCr response is in preparation as a path towards endorsement of the document that is sought from the IUCr by CODATA.

J. R. Helliwell, IUCr Representative, and B. McMahon, alternate IUCr Representative

\subsection{ICSU Committee on Space Research (COSPAR)}

COSPAR's (http://cosparhq.cnes.fr/) main objective is to promote international collaboration in scientific research in space, with an emphasis on the exchange of results, information and opinions. Developing world standards for the space environment and its protection requires the creation of national and international organizations and specialist working groups.

COSPAR's highest body is the Council. The Council comprises the Committee's President, Representatives of Member National Scientific Institutions and International Scientific Unions, the Chairs of COSPAR Scientific Commissions, and the Chair of the Finance Committee. The Council meets at the Committee's biennial Scientific Assembly. Between Assemblies the Bureau runs COSPAR on a day-today basis. COSPAR President for the period 2014-2018 is Lennard A. Fisk (USA) and the Vice-Presidents are J. Wu (People's Republic of China) and A. Jayaraman (India). Members of the Bureau are: Ines S. Batista (Brazil), C. Césarsky (France), K.-H. Glassmeier (Germany), M. I. Panasyuk (Russia), S. Sasaki (Japan) and J.-P. St.-Maurice (Canada).

COSPAR acts mainly as a body responsible for organizing biennial Scientific Assemblies and the 40th COSPAR Assembly was held in in Moscow, Russia, 2-10 August 2014. The next, the 41st, will be organized in Istanbul, Turkey, 30 July - 7 August 2016 (http://www.cospar-assembly.org/), followed by COSPAR 2018 in Pasadena, California, USA, 1422 July 2018.

Most COSPAR activities are related to space topics (astronomy, astrobiology, geophysics, atmosphere studies, investigation of natural and artificial ecosystems, as well as 
space travel). For the IUCr, the most interesting division of COSPAR is the Scientific Commission on Materials Science in Space (MSS Comission G), chaired by V. Shevtsova (Belgium) and co-chaired by S. Amiroudine (France), T. Koenemann, (Germany) and S. Yoda (Japan). This Commission coordinates fundamental experiments in materials and fluid sciences performed in space, utilizing reduced gravity for their objectives.

Advances in Space Research (ASR, http://ees.elsevier.com/ asr/, impact factor 1.358 in 2014) is the official journal of COSPAR. It covers all areas of space research, including - but not limited to - space studies of the earth surface, climate, meteorology, fundamental physics in space, materials physics in space, space debris, weather and earth observation of space phenomena. ASR also includes COSPAR's information bulletin, Space Research Today.

The new COSPAR journal, entitled Life Sciences in Space Research, will be available in PubMed in the next few months. Elsevier has created a virtual special issue with the five most cited papers to announce and 'celebrate' this news. The papers were freely available until 30 November 2015.

In 2015 the Director of Science announced the opportunity to solicit from the broad scientific community proposals for the competitive selection of new 'Science Ideas', to be investigated in terms of feasibility and needed technology developments. More information is available at http:// www.cosmos.esa.int/web/new-scientific-ideas.

Following the former discussion between the IUCr $(\mathrm{H}$. A. Dabkowska) and COSPAR (A. Janofsky and M. Mendez) representatives, the proposal for the mutual IUCr COSPAR Capacity Building Workshop on Crystallography for Space Science was submitted to COSPAR by Juan M. Garcia-Ruiz, Maria Eugenia Mendoza, Guillermo T. Tagle, Hanna A. Dabkowska and Mariano Mendez. This proposal was accepted and the Workshop will take place in Puebla, Mexico, 17-29 April 2016. The programme will present the fundamentals of crystallography, minerals in space, reports on crystallographic and crystal-growth experiments performed in space and actual and future investigation of space debris by crystallographic methods, including sample preparation and data collection. The IUCr will help to cover the costs of bringing young participants to this meeting and the costs of travel of three Visiting Professors, teaching crystallography basics. The topic of the workshop 'Crystallography for Space Sciences' is novel as this is the first workshop focused on a science that is becoming more and more important in some areas of space research. More information about this workshop can be found at http://www.inaoep.mx.

In 2015 COSPAR co-sponsored the following meetings:

International Reference Ionosphere 2015 Workshop, Improved Accuracy in the Equatorial Region and Progress toward a Real-time IRI Model, Bangkok, Thailand, 2-13 November 2015.

Planetary Missions Data Analysis, Guaratinguetá, São Paulo, Brazil, 26 October - 6 November 2015.

Earth Observation of Transboundary Water Resources, Ho Chi Minh City, Vietnam, 26 October - 6 November 2015.
To find out more about other COSPAR activities go to http://cosparhq.cnes.fr/events.

\section{H. A. Dabkowska, IUCr Representative \\ 10.6. International Organization for Standardization}

There were no activities during 2015 that related to crystallography.

\section{P. Brock, IUCr Representative}

\section{Finances}

Extracts from the full financial statements, namely the Income and Expenditure account, Balance Sheet and Summary of Fund Accounts, are given in Tables 1, 2 and 3, respectively. For comparison, the figures for 2014 are provided in italics. The accounts are presented in CHF.

The ICSU exchange rates, based on the official UN rates, have been used in the preparation of these accounts. As a consequence of the many fluctuations in exchange rates during the year, the following procedure has been adopted for the accounts. Assets and liabilities in currencies other than CHF at 31 December 2015 have been translated into CHF in the balance sheet at the rate operative at that date. For the income and expenditure accounts, transactions have been translated into CHF by applying the rates appropriate to the individual dates of these transactions. As a consequence of the fluctuation in exchange rates, overall an apparent loss has arisen on the assets of the Union, in terms of CHF, amounting to CHF 2364 . In the accounts this has been assigned as a 'Realized gain' (CHF 2 846) and 'Unrealized loss' (CHF 5 210). The loss attributable to investment activities has been assigned to the General Fund and the overall gain attributable to trading activities has been divided amongst the fund accounts in direct proportion to the balances on these accounts at 31 December 2015. It should be noted that this overall loss in CHF is not a real loss of money, but rather a loss on paper resulting from the accounts being expressed in CHF.

Investments are noted in the balance sheet at their market value at 31 December 2015.

The balance sheet shows that the assets of the Union, including the loss resulting from fluctuations in rates of exchange, have decreased during the year, from $\mathrm{CHF}$ 4299542 to CHF 3587 207. The movement in market value of the investments was CHF -86 731 in 2015 (CHF 95044 in 2014).

The following transfers were made from the Acta Crystallographica Fund: CHF 200000 to the Publications and Journals Development Fund; CHF 200000 to the Research and Education Fund. CHF 20000 was transferred from the Journal of Applied Crystallography Fund to the President's Fund; CHF 11656 was transferred from the General Fund to the Outreach and Education Fund.

The following comments refer to figures in the full accounts. 
Table 1

Income and Expenditure Account (in Swiss Francs) for the year ended 31 December 2015.

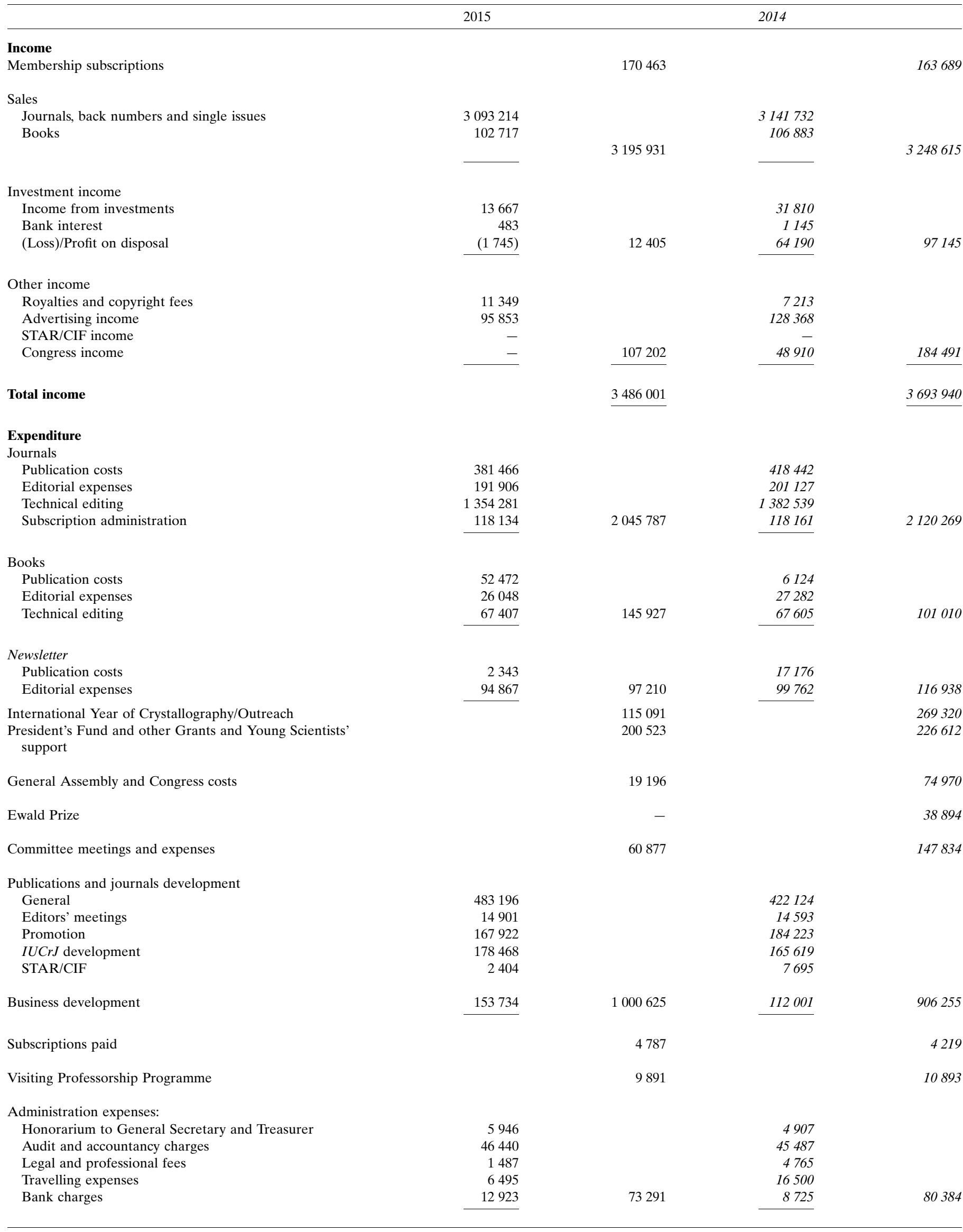


Table 1 (continued)

2015

Executive Secretary's office:

Salaries and expenses

Travel expenses of IUCr Representatives on other bodies

Sponsorship of meetings

President's secretary

IUCr/FIZ agreement

Bad debts

Commission expenses

Depreciation

Total expenditure

Deficit of income over expenditure (before realized exchange fluctuations)

Realized fluctuations in rates of exchange Exchange movement on trading activities

(Deficit) of income over expenditure (after realized exchange losses)

Movement in market value of investments in year

Unrealized fluctuation in rates of exchange

Exchange movement on trading activities

Investment activities

12482

(17 692)

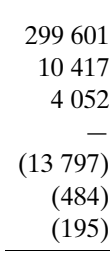

(195)

2014

Total recognized gains/(losses) relating to the year

Opening fund accounts at 1 January

Closing fund accounts at 31 December

$\frac{2846}{(620394)}$

299594

36442

4109241

(623 240)

(86 731)

(707 125)

(5 210)

(712 335)

4299542

3587207

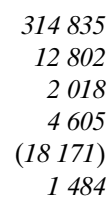

$\begin{array}{r}1484 \\ - \\ \hline\end{array}$

317573

41744

4456916

(762 976)

39946

(723 030)

95044

(627 985)

330985

(297000)

4596542

4299542

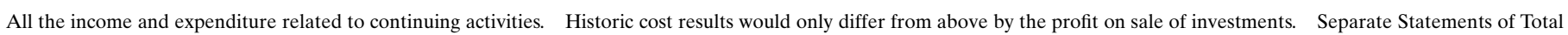
Recognized Gains and Losses and Reconciliation of Movements in the Fund Account are not given, as the information is incorporated in the above.

The General Fund account shows a deficit of CHF 351933 , as compared with a deficit in 2014 of $\mathrm{CHF} 364$ 388. The administrative expenses were CHF 375981 in 2015 as compared with CHF 411174 in 2014. Of this amount, CHF 166603 was charged to the publications of the Union.

The expenses of the Union Representatives on other bodies were CHF 10 417. The cost of the Finance Committee meetings held in 2015 was CHF 21800 , while the Executive Committee meetings cost CHF 39077 . The income from the IUCr/Fachinformationszentrum agreement (to provide lowcost copies of the Inorganic Crystal Structure Database) was CHF 13 797. The subscriptions from Adhering Bodies were CHF 169706 . Interest on bank accounts and investments credited to the General Fund was CHF 14150.

Grants totalling CHF 6147 were paid from the President's Fund in 2015.

The Journals Funds accounts for 2015 shows a surplus of CHF 445335 before the transfer of CHF 420000 to the other fund accounts, as compared with a surplus of CHF 551212 in 2014 before the transfer of CHF 540000 to the other fund accounts.
The cost of the technical-editing office has been divided between the Journals Fund and the International Tables Fund in percentages based on the staff time spent on each publication. The technical-editing costs for the Journals Funds were CHF 1342706 as compared with CHF 1345603 in 2014. The Journals Funds have also been charged with administration expenses as in previous years as shown in the General Fund.

The International Tables account shows a deficit of CHF 103 403, as compared with a deficit of CHF 53497 in 2014. The net sales income was CHF 76968 in 2015 as compared with CHF 79100 in 2014.

The cost for the Union in producing the Newsletter in 2015 was CHF 40005.

In the Publications and Journals Development Fund account, the computing, business development and promotion expenses are divided between the General Fund, the Journals Fund and the International Tables Fund. STAR/CIF costs, $I U C r J$ development costs, Special Issue costs, archiving and web input costs are also charged to the Publication and Journals Development account. 
Table 2

Balance sheet (in Swiss Francs) as at 31 December 2015.

2015

Fixed assets

Tangible fixed assets

Investments at market value

\section{Current assets}

Stock

Cash at bank and in hand

Current accounts

Deposit and savings accounts

Cash with Union officials

Debtors, accrued income and payments in advance

Subscriptions due from Adhering Bodies

Total current assets

Creditors: amounts falling due within one year

Net current assets

Total assets being total funds
2014
25918

3444881

$\overline{3470799}$

131148

66028

954202

21727

62222

$\begin{array}{r}125274 \\ 1264126 \\ 1041957 \quad 26287 \\ \hline\end{array}$

1415687

344750

1481882

1827920

(1 038 167)

(999 177)

443715

828743

3587207

4299542

Table 3

Summary of Fund Accounts (in Swiss Francs) as at 31 December 2015.

\begin{tabular}{|c|c|c|c|c|c|c|c|}
\hline & \multirow{2}{*}{$\begin{array}{l}\text { As at } \\
1 \text { January } 2015\end{array}$} & \multirow[t]{2}{*}{$\begin{array}{l}\text { Transfers } \\
\text { between } \\
\text { funds }\end{array}$} & \multirow[t]{2}{*}{$\begin{array}{l}\text { (Deficit)/ } \\
\text { surplus of } \\
\text { income over } \\
\text { expenditure } \\
\text { for the } \\
\text { year }\end{array}$} & \multirow[t]{2}{*}{$\begin{array}{l}\text { Increase in } \\
\text { market } \\
\text { value of } \\
\text { investments }\end{array}$} & Fluctuations & n exchange rates & \multirow[t]{2}{*}{$\begin{array}{l}\text { Balance } \\
\text { at } 31 \text { December } \\
2015\end{array}$} \\
\hline & & & & & Trading & Investments & \\
\hline \multicolumn{8}{|l|}{ Fund accounts } \\
\hline General Fund & $(2934409)$ & $(11656)$ & (351 933) & $(86731)$ & $(11760)$ & $(17$ 692) & (3 4144181$)$ \\
\hline President's Fund & 135130 & 20000 & $(6$ 147) & - & 518 & - & 149501 \\
\hline Acta Crystallographica Fund & 4598272 & $(400000)$ & 424397 & - & 16061 & - & 4638730 \\
\hline Journal of Applied Crystallography Fund & 798577 & $(20000)$ & 9964 & - & 2740 & - & 791281 \\
\hline International Tables & (619 954) & - & $(103403)$ & - & $(2513)$ & - & $(725870)$ \\
\hline Publications and Journals Development Fund & 747691 & 200000 & $(219540)$ & - & 2530 & - & 730681 \\
\hline Research and Education Fund & 728178 & 200000 & $(383281)$ & - & 1893 & - & 546790 \\
\hline Ewald Fund & 548924 & - & - & - & 1907 & - & 550831 \\
\hline Newsletter Fund & 5074 & - & $(40005)$ & - & $(121)$ & - & $(35052)$ \\
\hline Journal of Synchrotron Radiation Fund & 21886 & - & 10974 & - & 114 & - & 32974 \\
\hline General Assembly and Congress & 270173 & - & (19 196) & - & 872 & - & 251849 \\
\hline \multirow[t]{2}{*}{ Outreach and Education } & - & 11656 & 57776 & - & 241 & - & 69673 \\
\hline & 4299542 & - & (620 394) & $(86731)$ & 12482 & $(17$ 692) & 3587207 \\
\hline
\end{tabular}

CHF 191714 for financial support to young scientists, to enable them to attend scientific meetings sponsored by the Union, was charged to the Research and Education Fund. Visiting Professorships (CHF 9 891), outreach and education costs (CHF 103 387), IYCr costs (CHF 69 480) and interregional bursaries ( $\mathrm{CHF} 10249$ ) were also charged to the Research and Education Fund.
In 2007 a General Assembly and Congress Fund was established so that the costs associated with the General Assembly and Congress could be spread over the triennium. In 2015 the expenses charged to this Fund were CHF 19196.

An Outreach and Education Fund has been established. In 2015 donations totalling CHF 98824 were received. 